\title{
Dissecting the multi-scale spatial relationship of earthworm assemblages with soil environmental variability
}

\author{
Juan J Jiménez ${ }^{1 * \dagger}$, Thibaud Decaëns ${ }^{2 \dagger}$, Patrick Lavelle ${ }^{3}$ and Jean-Pierre Rossi ${ }^{4+}$
}

\begin{abstract}
Background: Studying the drivers and determinants of species, population and community spatial patterns is central to ecology. The observed structure of community assemblages is the result of deterministic abiotic (environmental constraints) and biotic factors (positive and negative species interactions), as well as stochastic colonization events (historical contingency). We analyzed the role of multi-scale spatial component of soil environmental variability in structuring earthworm assemblages in a gallery forest from the Colombian "Llanos". We aimed to disentangle the spatial scales at which species assemblages are structured and determine whether these scales matched those expressed by soil environmental variables. We also tested the hypothesis of the "single tree effect" by exploring the spatial relationships between root-related variables and soil nutrient and physical variables in structuring earthworm assemblages. Multivariate ordination techniques and spatially explicit tools were used, namely cross-correlograms, Principal Coordinates of Neighbor Matrices (PCNM) and variation partitioning analyses.
\end{abstract}

Results: The relationship between the spatial organization of earthworm assemblages and soil environmental parameters revealed explicitly multi-scale responses. The soil environmental variables that explained nested population structures across the multi-spatial scale gradient differed for earthworms and assemblages at the very-fine- $(<10 \mathrm{~m})$ to medium-scale $(10-20 \mathrm{~m})$. The root traits were correlated with areas of high soil nutrient contents at a depth of $0-5 \mathrm{~cm}$. Information on the scales of PCNM variables was obtained using variogram modeling. Based on the size of the plot, the PCNM variables were arbitrarily allocated to medium $(>30 \mathrm{~m})$, fine $(10-20 \mathrm{~m})$ and very fine scales $(<10 \mathrm{~m})$. Variation partitioning analysis revealed that the soil environmental variability explained from less than $1 \%$ to as much as $48 \%$ of the observed earthworm spatial variation.

Conclusions: A large proportion of the spatial variation did not depend on the soil environmental variability for certain species. This finding could indicate the influence of contagious biotic interactions, stochastic factors, or unmeasured relevant soil environmental variables.

\section{Background}

Ecological processes are spatially influenced on various scales, ranging from global to local scales [1,2]. In natural communities, the observed spatial pattern is the result of environmental, biological and/or historical drivers [3], which are not exclusive but rather complementary. The existence of spatial structures of species assemblages

\footnotetext{
* Correspondence: jjimenez@ipe.csic.es

${ }^{\dagger}$ Equal contributors

'Department of Biodiversity Conservation and Ecosystem Restoration, Pyrenean Institute of Ecology (IPE), Spanish National Research Council (CSIC), Jaca (Huesca) ES-22700, Spain

Full list of author information is available at the end of the article
}

suggests the influence of at least one structuring factor: i) a spatially distributed environment is the driving force that structures species assemblages according to niche theory [4]; ii) species are assembled on certain spatial scales through the influence of biotic interactions [5-10]; and iii) historical contingency, according to neutral theory $[10,11]$, or stochastic variations in the history of species arrival $[12,13]$ drive this process, although the scale of the random effect has not been fully identified [14]. It is challenging to determine which process has a larger effect because historical species arrival data and past ecological processes are usually unknown. 
When analyzing spatial datasets, striking and puzzling results are found if spatial autocorrelation is ignored because response variables are structured on various spatial scales [15-18]. Specific spatially explicit sampling protocols for targeted organisms and different approaches are needed in soil ecology studies $[17,19,20]$, although these methods must be used with caution [16,21]. Geostatistics [22] allows the assessment of the spatial distribution of soil environmental variability and soil organisms [22,23], but other powerful statistical tools are necessary to model spatial structures on various scales, such as principal coordinates of neighbor matrices (PCNM) $[3,24,25]$. The PCNM approach is part of the distance-based Moran's eigenvector map (MEM) analysis, which is included in the spatial eigenfunction family of tools $[2,25,26]$ and is a powerful statistical method to model spatial structures at all scales; in other words, the environmental variability is linked to community structure on a multi-scale level [3,24] to obtain new ecological insights [21]. It has also been used to test and separate the niche from neutral mechanisms that influence the community structure [15], although it may appear over-simplistic [27,28].

To date, few field studies have been performed on the assembly of soil invertebrate communities to infer overall patterns and draw conclusions on the importance of explicitly accounting for multi-spatial scales. Soil organism communities have been reported to be spatially structured due to their response to spatial variability in soil resources [12,19,29-33], allowing the co-existence of competing species within the same patch in spatially heterogeneous environments [32,34]. Although complex spatial patterns have been described for soil invertebrates forming patch assemblages that range from the scale of soil aggregates [35] to those of individual plants [36], agricultural lands and natural ecosystems [37-42], no study has assessed the multi-scale spatial relationship between soil invertebrates and environmental variability thus far. The influence of disturbance and habitat heterogeneity on Carabidae assemblages has been described recently, but only on the landscape scale [19]. Studies and data analysis using these multi-spatial analysis techniques to perform invertebrate community research are needed, even if caution must also be exercised [43]. In this study, we aimed to i) analyze the spatial location of significant patches and gaps of the species assemblages identified, ii) test whether the relationship between species assemblages and soil environmental variability occurs on very fine $(<10 \mathrm{~m})$, fine $(10-20 \mathrm{~m})$, and medium scales $(>30 \mathrm{~m})$, and iii) investigate the spatial relationship between root traits and soil parameters to test the hypothesis of the "single tree effect" [44].

\section{Results}

\section{Earthworm abundance and soil environmental} heterogeneity

A total of 688 earthworms were collected and included seven species (Table 1) with three main ecological categories present [45]: epigeics (litter feeders), Aymara sp. and one unclassified species (new genus 1); endogeics (soil feeders), Andiodrilus sp., Andiorrhinus sp., Glossodrilus sp., and one unclassified species (new genus 2); and anecics (soil + litter feeders), Martiodrilus sp.

The CA extracted three axes $(72.9 \%$ of the total variance), and these three axes were used to discriminate among the various species assemblages according to the axis selected (Figure 1). Axis I (34.2\% of the explained variance) discriminated new genus 1 versus all other species, whereas the second axis (21.7\% of the total variance) revealed a clear distinction between endogeic and epigeic + anecic species. Moreover, the position of species along the positive side of axis 2 followed a body size increase among endogeic species. Axis 3 (17.1\% of the total variance) separated Aymara, Andiodrilus and new genus 1 from Martiodrilus, Glossodrilus and new genus 2.

\section{Patches and gaps of species assemblages}

The SADIE spatial $\mathrm{I}_{\mathrm{a}}$ index and local $\mathrm{v}_{\mathrm{i}}$ and $\mathrm{v}_{\mathrm{j}}$ clustering indices were statistically significant for endogeic species and the group Martiodrilus, Glossodrilus and new genus 2 ( 1 anecic +2 endogeics), whereas only the $\mathrm{v}_{\mathrm{j}}$ index was significant for Andiodrilus, Aymara and new genus 1, i.e. one endogeic + two epigeics (Table 2). Significant spatial dissociations were found when using those assemblages identified with CA axes, i.e., $-0.232(\mathrm{p}=0.978)$ between new genus 1 and the rest of species, $-0.278(\mathrm{p}=0.995)$ between endogeics and epigecis + anecic group, and -0.383 ( $\mathrm{p}=0.999$ ) between the group Andiodrilus, Aymara and new genus 1 from Martiodrilus, Glossodrilus and new genus 2 group.

The number of significant clusters of the earthworm assemblages ranged from 1 (new genus 1) to 9 (endogeics), with gaps occupying a larger area than that of patches (Figure 2). The type of litter and tree root traits may influence the patchy distribution of endogeic earthworms, which is known as the "single tree effect" [44]. The endogeic species assemblage was close to $A$. maripa trees, except for the large patch at the central part of the surveyed plot, where values of the coarse root length and weight (CoRL, CoRW) were the lowest (Figure 3, kriged contour maps).

The identity and location of tree species within the surveyed plot did not appear to explain the observed spatial patterns of the remaining species assemblages:

- new genus 1: a significant gap in the lower half area where multiple tree species, mainly $A$. maripa, were present. The correlogram was not significant (Figure 4a).

- All other species: significant gaps and patches were not linked to areas of tree presence. The correlogram was not significant (Figure 4a). 
Table 1 Earthworm abundance and main morphological traits

\begin{tabular}{|c|c|c|c|c|c|c|c|c|}
\hline \multirow[t]{2}{*}{ Species } & \multirow[t]{2}{*}{ Family } & \multirow[t]{2}{*}{ Ecological category ${ }^{1}$} & \multirow[t]{2}{*}{ Pigmentation } & \multicolumn{2}{|c|}{$\operatorname{Size}^{2}(\mathrm{~mm})$} & \multirow{2}{*}{$\begin{array}{l}\text { Weight }^{2} \\
\text { (g.f.w.) }\end{array}$} & \multirow[t]{2}{*}{$\mathbf{N}$} & \multirow{2}{*}{$\begin{array}{l}\text { Average density } \\
\pm \text { standard error }\end{array}$} \\
\hline & & & & Length & Diam. & & & \\
\hline Andiodrilus sp. & Glossoscolecidae & Endogeic & Unpigmented & 109.0 & 4.4 & 1.38 & 22 & $3.1 \pm 0.7$ \\
\hline Andiorrhinus sp. & Glossoscolecidae & Endo-anecic & Pink anterodorsal & 188.0 & 7.6 & 7.10 & 10 & $0.1 \pm 0.1$ \\
\hline Aymara sp. & Glossoscolecidae & Epigeic & Dark-red dorsal & 58.1 & 1.5 & 0.06 & 15 & $6.5 \pm 1.3$ \\
\hline New genus 1 & $N C^{3}$ & Epigeic & Dark-green dorsal & 117.9 & 3.8 & 0.69 & 18 & $9.5 \pm 5.1$ \\
\hline Glossodrilus sp. & Glossoscolecidae & Endogeic & Unpigmented & 83.9 & 1.5 & 0.10 & 13 & $8.5 \pm 1.4$ \\
\hline Martiodrilus sp. & Glossoscolecidae & Anecic & Dark-grey anterodorsal & 194.3 & 9.3 & 11.2 & 29 & $10.3 \pm 1.4$ \\
\hline New genus 2 & Ocnerodrilidae & Endogeic & Unpigmented & 22.8 & 0.7 & 0.006 & 157 & $24.0 \pm 2.6$ \\
\hline
\end{tabular}

${ }^{1}$ Epigeic: live and feed on the soil surface; Endogeic: live and feed within the soil; Anecic: live within the soil and dig vertical or semi-vertical burrows to feed on the soil surface (after $[45,46])$. Endo-anecic worms have characteristics of anecic (anterodorsal pigmentation, flattened rear end) and endogeic worms (horizontal burrowing).

${ }^{2}$ Average biometric data for adults (g.f.w.indicates grams of fresh weight in $4 \%$ formalin, gut contents included).

${ }^{3} \mathrm{NC}$ : not classified.

- Endogeics group: four significant patches close to the location where the A. maripa tree species was observed. The correlogram was significant (Figure 4b). - epigeics + anecic group: same as described for the rest of species (CA1-). The correlogram was not significant (Figure 4b).

- Andiodrilus, Aymara and new genus 1: two significant gaps in the lower half area and two significant patches in the plot edge where the $A$. maripa tree species was found. The correlogram was not significant (Figure 4c).

- Martiodrilus, Glossodrilus and new genus 2 group: one significant patch in the western zone of the plot where trees were present and a large significant gap in the upper part; another two significant patches were in the eastern zone. The correlogram was significant (Figure 4c).

\section{Cross-correlogram analysis}

Regarding the spatial cross-correlation between rootrelated variables and soil nutrient-related and physical variables, significant positive cross-correlations were identified at short lag distances (h) between the FiRL and $\mathrm{SOC}_{0-5}, \mathrm{P}_{0-5}$ and $\mathrm{C:N} \mathrm{N}_{5-10}$ (Table 3 ), whereas $\mathrm{P}_{5-10}$ showed a significant negative cross-correlation (Monte Carlo permutation). With regard to the CoRL, the crosscorrelation at short distances was positive for $\mathrm{SOC}_{5-10}$ and $\mathrm{C}: \mathrm{N}_{5-10}$ and negative for $\mathrm{N}_{5-10}$ and $\mathrm{P}_{5-10}$. Regarding root biomass, the FiRW showed significant positive spatial cross-correlation with $\mathrm{P} 0-5$ and $\mathrm{P}_{5-10}$, whereas it was negative for the variables $\mathrm{SOC}_{5-10}, \mathrm{C}: \mathrm{N}_{0-5}$ and $\mathrm{C}$ : $\mathrm{N}_{5-10}$ at short lag distances (Table 3). The CoRW showed a positive spatial relationship with $\mathrm{SOC}_{5-10}$ and $\mathrm{C}: \mathrm{N}_{5-10}$ and a negative relationship with $\mathrm{P}_{5-10}$. A significant positive spatial cross-correlation was observed between the FiRL and soil aggregates of less than $5 \mathrm{~mm}$ in size, whereas it was negative for larger soil aggregates and moisture at short lag distances (Table 4). Regarding the FiRW, a significant negative spatial cross-correlation at short distances was especially observed for $<0.5$ and 2-5 mm size soil aggregates, and a positive crosscorrelation was observed for $>10 \mathrm{~mm}$ aggregates and bulk density (BD). Finally, the CoRL showed a positive spatial cross-correlation with $0.125-0.5$ and $1-5 \mathrm{~mm}$ soil aggregates and hydraulic conductivity, and a negative spatial cross-correlation was observed for $>10 \mathrm{~mm}$ soil aggregates and soil moisture. The CoRW showed a positive spatial cross-correlation with $0.125-0.25$ and $0.5-5 \mathrm{~mm}$ size soil aggregates and a negative spatial cross-correlation for $>10 \mathrm{~mm}$ soil aggregates (Table 4).

\section{Decomposing multiple scale spatial patterns of species assemblages}

Significant multi-scale spatial structures were obtained for the earthworm community, species and assemblages, especially in the case of new genus 1 . The forward selection procedure resulted in various numbers of PCNM variables, ranging from 1 to 9 out of 69 positively autocorrelated spatial eigenvectors (significant Moran's I at $\mathrm{p}<0.05)$. Variogram modeling [25] provided information on the scales of PCNM variables. The PCNM eigenfunctions selected to model the distribution of earthworm community are depicted in the Additional file 1.

These parameters indicate clear spatial structures on a medium $(>30 \mathrm{~m})$, fine $(10-20 \mathrm{~m})$ and very fine scale $(<10 \mathrm{~m})$, except for Andiodrilus (which presented only one significant PCNM). Regarding new genus 1, PCNM3 and PCNM8 defined the medium-scale patterns, whereas PCNM12 and PCNM16 encompassed the fine-scale patterns; PCNM29, PCNM33 and PCNM51 described very fine scales (Additional file 1). The maps of the fitted scores of the significant canonical axes in the PCNM analysis for 

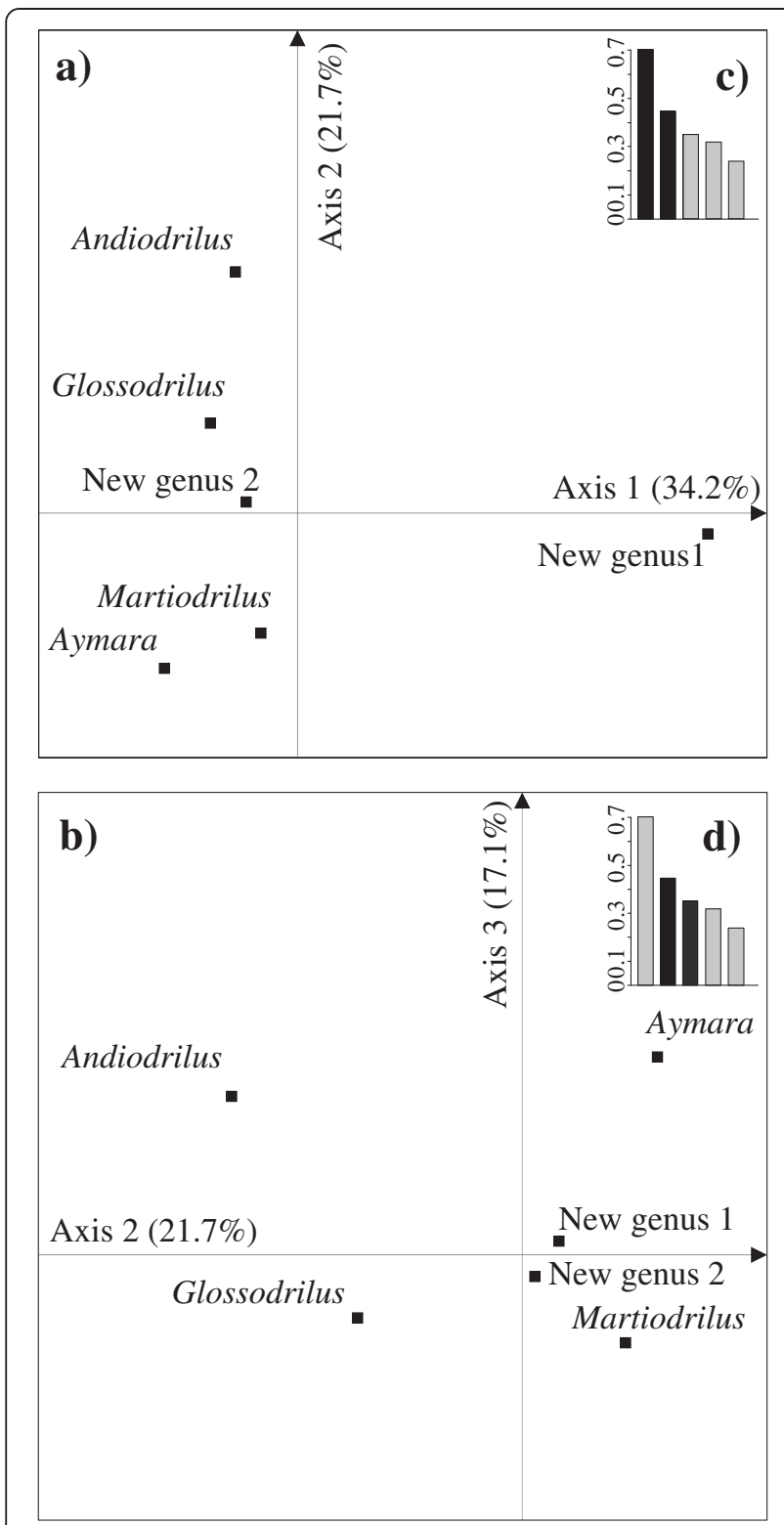

Figure 1 Ordination plot of species in the factorial plan following correspondence analysis of earthworm density $\left(\mathrm{N} \mathrm{m}^{-2}\right)$ in the gallery forest: (a), axes 1 and 2; (b), axes 2 and 3; and (c) and (d), "eigenvalues". The species Andiorrhinus was not included in the analysis because it only represented $1 \%$ of the total earthworm abundance.

species (A), species assemblages and the whole community (B) are depicted in Additional file 2.

The significant explanatory environmental variables that best described the multi-spatial structure varied for the earthworm community, species and species assemblages (Table 5). The nutrient-related variables explained much of the structure of new genus 1 on the medium and fine scales, whereas the physical variables were
Table 2 SADIE aggregation indices and associated $p$ levels for the various combinations of earthworm assemblages identified in the three axes extracted from the CA

\begin{tabular}{llll}
\hline Species assemblages & $\mathbf{l}_{\mathbf{a}}$ & $\mathbf{v}_{\mathbf{i}}$ (patch) & $\mathbf{v}_{\mathbf{j}}$ (gap) \\
\hline New genus 1 & $0.997 \mathrm{NS}$ & $0.871 \mathrm{NS}$ & $-1.003 \mathrm{NS}$ \\
Rest of species & $1.018 \mathrm{NS}$ & $0.944 \mathrm{NS}$ & $-1.015 \mathrm{NS}$ \\
Endogecis & $1.414^{*}$ & $1.485^{* *}$ & $-1.430 *$ \\
Epigeics + Anecic & $1.011 \mathrm{NS}$ & $1.188 \mathrm{NS}$ & $-1.061 \mathrm{NS}$ \\
$\begin{array}{l}\text { Andiodrilus, Aymara and new } \\
\text { genus 1 }\end{array}$ & $1.222 \mathrm{NS}$ & $1.343^{*}$ & $-1.222 \mathrm{NS}$ \\
$\begin{array}{l}\text { Martiodrilus, Glossodrilus and } \\
\text { new genus 2 }\end{array}$ & $1.453 *$ & $1.320^{*}$ & $-1.428 *$ \\
\end{tabular}

$\mathrm{l}_{\mathrm{a}}=$ global index of aggregation; $\mathrm{v}_{\mathrm{j}}=$ mean negative index value (gap); $v_{i}=$ mean positive index value (patch). Departure from randomness is tested using 5,967 permutations. ${ }^{*} p<0.05 ;{ }^{* *} p<0.01$; NS, not significant.

better explained on a very fine scale, such as soil compaction (negatively) and humidity (positively). The variables $\mathrm{C}_{0-5}$ $\left(\mathrm{p}_{\text {corr }}<0.001\right)$ and moisture content $\left(\mathrm{p}_{\text {corr }}<0.05\right)$ contributed positively to the spatial structure model of new genus 1 , whereas $\mathrm{C}_{5-10}$ ( $\left.\mathrm{p}_{\text {corr }}<0.05\right), \mathrm{N}_{0-5}\left(\mathrm{p}_{\text {corr }}<0.001\right), \mathrm{C}: \mathrm{N}_{0-5}$ $(\mathrm{p}<0.01)$ and compaction $\left(\mathrm{p}_{\mathrm{corr}}<0.05\right)$ contributed negatively to medium-scale patterns (Table 5).

With regard to the endogeic Andiodrilus sp., the medium-scale spatial structure was explained by physical variables associated with the size of soil aggregates, although the values were not significant $\left(\mathrm{p}_{\mathrm{corr}}>0.05\right)$. When species assemblages were used instead, new environmental variables were detected (Table 5), i.e., variable $\mathrm{P}_{0-5}$ was negatively correlated to the medium-scale pattern of assemblage of endogeics, and litter contributed negatively to this pattern. For the epigeics and anecic assemblage, litter and moisture contributed positively to the medium-scale spatial structure model, although this contribution was not significant $\left(\mathrm{p}_{\mathrm{corr}}>0.05\right)$.

\section{Soil environmental control on earthworm species and assemblage spatial patterns}

The variation partitioning analysis revealed differences among species regarding the explanatory variables (Table 6). The entire set of environmental and spatial variables explained the various percentages of variation within the community, species and species assemblage. In the case of the earthworm community, the explained variation was $41.9 \%$, of which $32.3 \%$ was explained by the soil environment but not the spatial variables $(p=0.005)$. The environment and fine-scale structure explained $4.98 \%$ of the total variation, whereas the environment and medium-scale structure together explained $2.93 \%$. For the species alone, the $\mathrm{R}_{\mathrm{a}}{ }^{2}$ coefficient for the environmental fraction ranged from $1 \%$ for Aymara to $48.0 \%$ for new genus 1. The medium and fine spatial scales explained $15.4 \%$ and $13.4 \%$ 


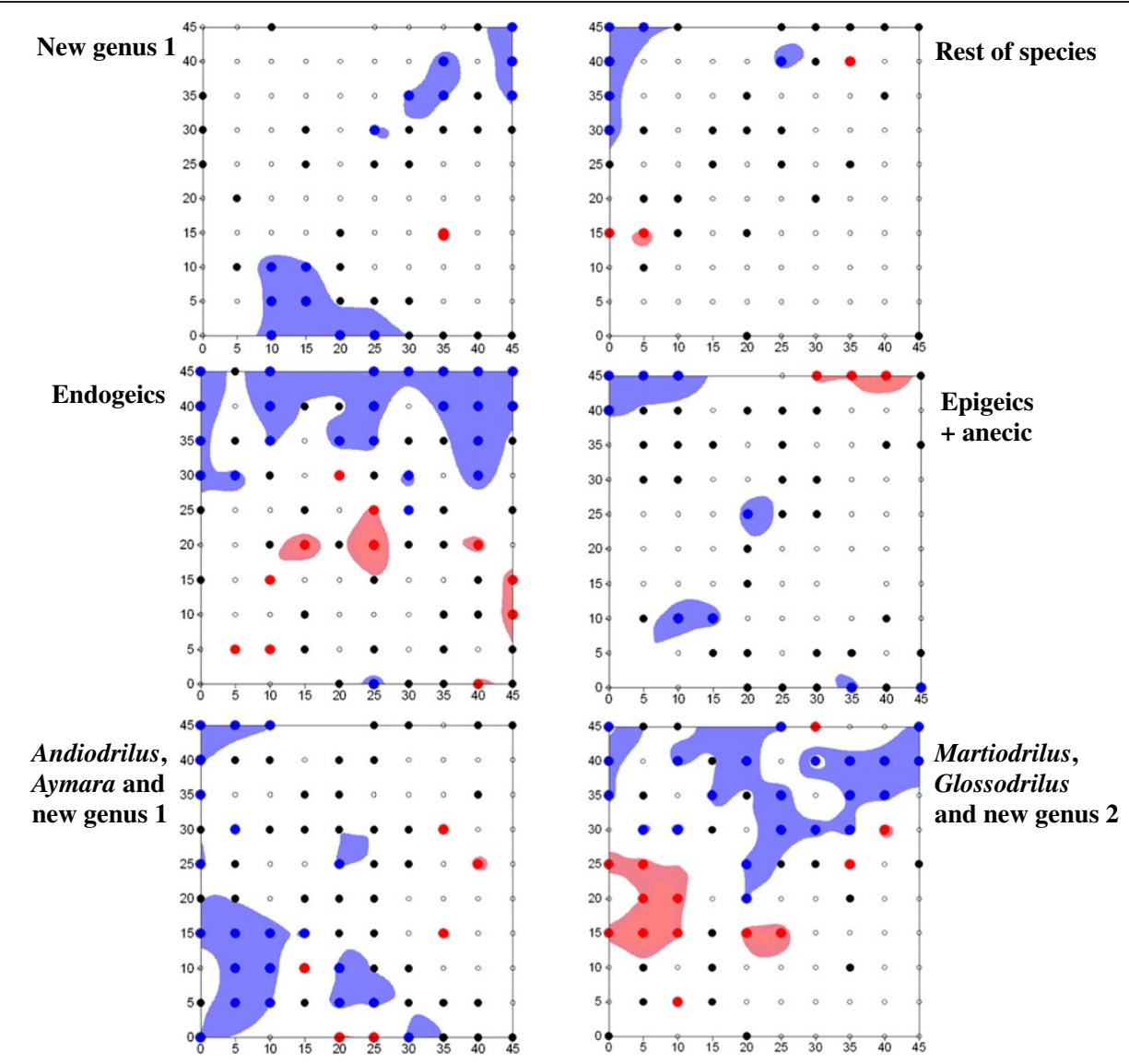

Figure 2 Overlaid contour and classed post maps (surfer) of SADIE clustering indices for counts of the species assemblages identified in the CA. Index values $>-1.5$ represent significant gaps (blue shading and darker blue dots), and index values $>1.5$ indicate significant patches (red shading and darker red dots). Black dots indicate units for which clustering exceeds expectation, although not significantly $(>2$ or $<-1)$. Open dots indicate clustering below expectation $(<1$ or $>-1)$.

for Aymara and 2\% and 2.2\% for new genus 1, respectively. The amount of variation explained only by spatial variables independent of the environment differed among species; it ranged from $1.3 \%$ to $28.8 \%$ for new genus 2 and Aymara, respectively (Table 6).

\section{Discussion}

Both spatial and environmental variables structured the species, assemblages and earthworm community, although variations were found in the explained contribution of environmental factors, i.e., $33.3 \%$ of the total variation of the global spatial structure of the earthworm community was explained by soil environmental variability. The specific soil environmental variables that were significantly linked to particular spatial scales for species and assemblages were also observed in other studies of nematodes in a forest [35]. To a certain extent, our results agree with Hutchinson's environmental control model [4], although a large portion of the variation was also linked to a purely spatial component (Table 6).
The selected PCNM variables highlighted significant spatial patterns in earthworm assemblages from a gallery forest, allowing us to identify the spatial scale at which the earthworm community was structured. In general, the very fine scale of autocorrelation detected in our study represents spatial patterns of less than $10 \mathrm{~m}$ (PCNMs 33, 51; Figure S1 in Additional file 1), fine scales depicted patterns of 15-20 m (PCNMs 12), and medium scales (PCNMs 3, 5, 8) represented spatial patterns of $>30 \mathrm{~m}$ (see details in Additional file 1). Furthermore, our observation of very fine-, fine- and medium-scale spatial relationships indicates the importance of considering multiple scales during ecological studies of soil organisms. In our study, we carefully chose the scale used to sample earthworms to focus on small-scale patterns. Additional studies are needed to increase the scale of the sampling design, i.e., hundreds of meters to several kilometres.

The influence of environmental constraints on the spatial distribution of species assemblages has previously 


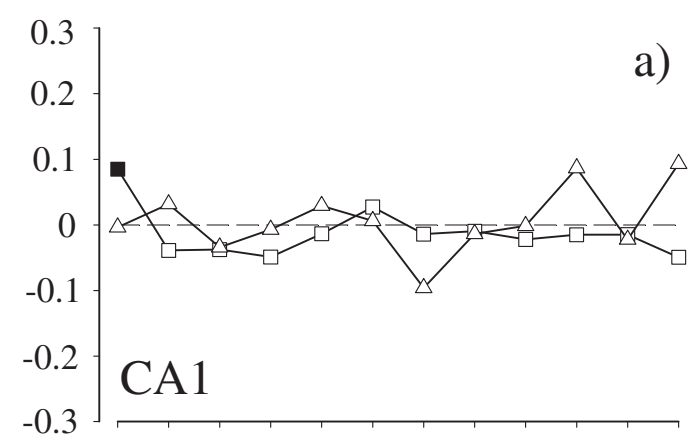

71115202428323641454953

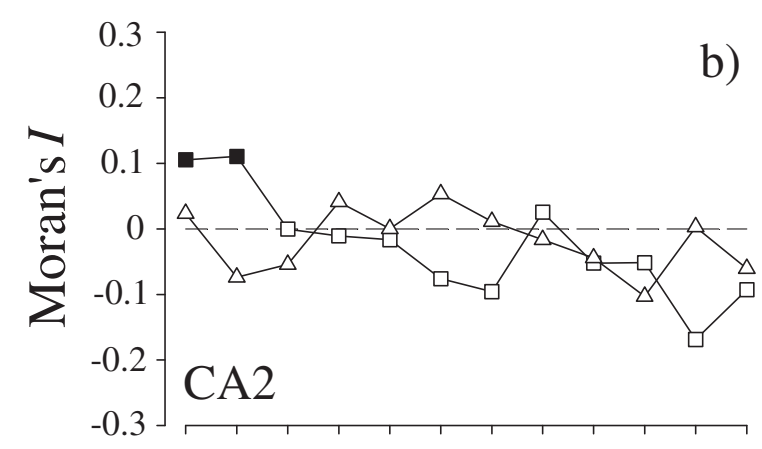

71115202428323641454953

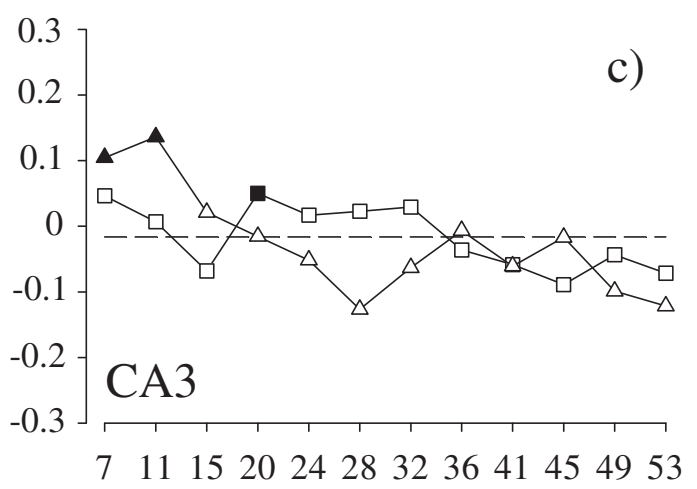

Distance (m)

Figure 3 Correlogram computed using the factorial coordinates for the corresponding positive ( $\square$ ) and negative $(\Delta)$ row scores of the three axes extracted from the CA depicting the spatial autocorrelation of a) assemblages CA1+ (New genus 1$)$ and CA1- (rest of species), b) CA2+ (endogeics) and CA2- (epigeics + anecic), and c) CA3+ (Andiodrilus, Avmara, new genus 1) and CA3(Martiodrilus, Glossodrilus and new genus 2). Black symbols refer to the lag distances at which the Moran's I coefficients were significant after progressive Bonferroni corrected $p$-values $\left(p=0.05 / 12 ; p^{\prime}=\right.$ 0.0042). Only the correlograms of the CA2+ and CA3-assemblages were globally significant.

been demonstrated in a nearby savanna [29]. Moreover, earthworm activity also contributes to soil heterogeneity $[33,37]$. The joint influence of the soil environment and species-created heterogeneity, i.e., the so-called "functional domain" [47] of soil parameters, could explain the spatial patterns observed on several scales. On very fine scales, the environmental variables associated with the spatial distribution of earthworms were more difficult to detect, i.e., the concentration of soil $\mathrm{C}_{0-5}$ and moisture better explained the spatial pattern of new genus 1 on fine and medium scales compared with very fine scales, whereas Andiodrilus sp. was mostly associated with physical variables, such as size class aggregated distributions, because this mediumsize species produces compact casts that influence the surrounding soil environment [32]. Very fine scales (PCNMs 32 and 50) may be overlooked by classical multivariate analyses, as their relationships may be masked by those of other explanatory variables associated with larger scales, such as PCNM 3. As a detailed analysis of the soil environmental variables was performed within a relatively small area, some of the variation could be attributed to unmeasured variables, leading to incomplete predictions [48]. Moreover, the fraction attributed solely to space was smaller than all other fractions, except for Aymara (28.8\%), Glossodrilus (14.1\%), and assemblages epigeics + anecic and Andiodrilus, Aymara and new genus 1, which represented $23.5 \%$ and $22.2 \%$ of the total variance, respectively.

The factors affecting the spatial distribution of soil organisms at larger scales include gradients in soil organic matter and vegetation structure [49], whereas at very fine scales $(<10 \mathrm{~m})$ earthworm spatial distribution could be influenced by local factors, such as the plant characteristics, soil moisture and micro-topography. A variety of plant species is likely to support important levels of soil heterogeneity [50]. The root architecture or fine-scale spatial patterns within the plant community determine the spatial structures of earthworm populations through fine-scale soil environmental variations, which is known as the "single-tree effect" [44]. Through litter input and root leachates, trees directly influence earthworm populations. They also indirectly influence earthworm populations by altering the soil properties, forming patches beneath tree canopies that influence community structure and ecosystem function [51,52]. Species exclusion was also reported for the savanna grass Imperata brasiliensis, as earthworms become injured upon contact with its sharp-pointed roots [38]. In our study, significant positive cross-correlations were found for the CoRL and CoRW and the soil nutrientand physical-related variables. These close associations between soil variables and vegetation structure have also been described for epigeic invertebrate assemblages [19]. Regarding the importance of soil environmental variables, it should be noted that the influential factors according to our analyses did not operate independently but interacted (e.g., root traits and nutrients); these complex interactions are characteristic of most ecological systems [53]. 


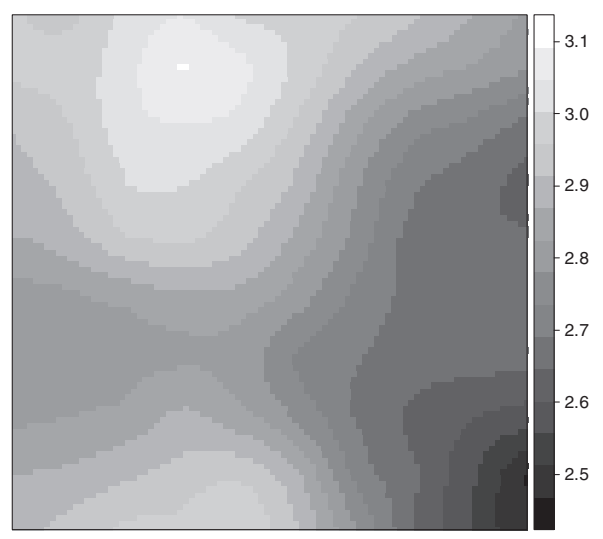

a) Fine root length

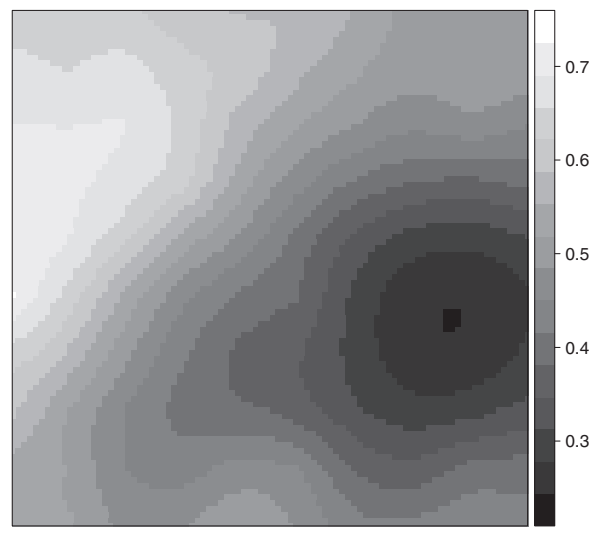

c) Coarse root length

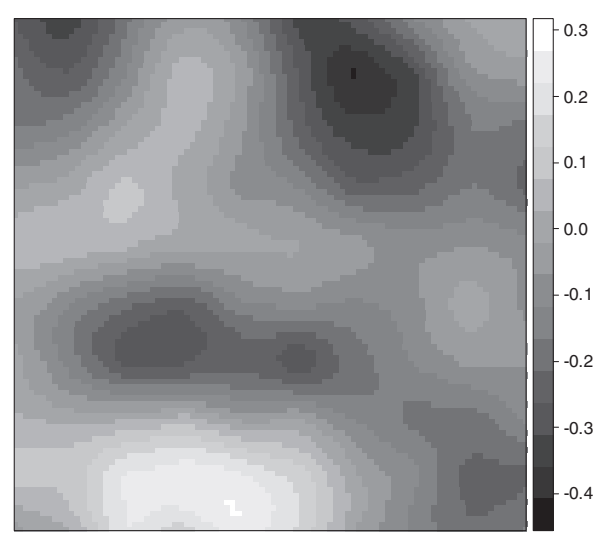

b) Fine root weight

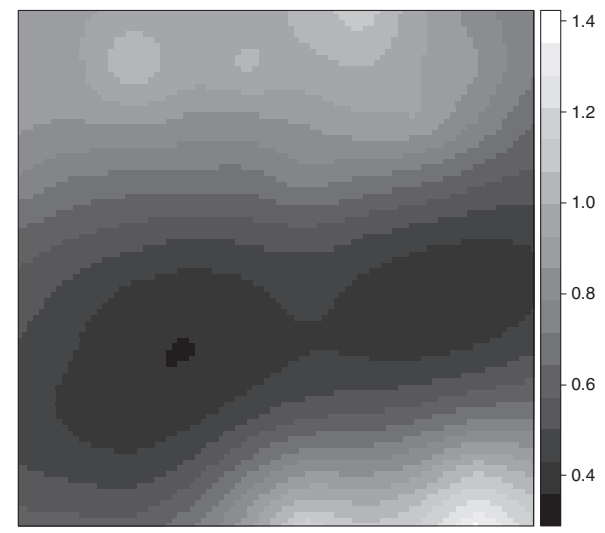

d) Coarse root weight

Figure 4 Kriged maps of root-related variables (log-transformed values): FiRL (a) and CoRL (c), length of fine and coarse roots, respectively $\left(\mathrm{m}\right.$ sample $\left.{ }^{-1}\right)$, and FiRW (b) and CoRW (d), weight of fine and coarse roots, respectively (g dry weight sample ${ }^{-1}$ ).

The idea that species distributions can be linked to key abiotic variables on multiple scales is not new [54]. Our analysis for empirical data has shown that environmental variables are indeed most important on broad scales, whereas purely spatial patterns appear to dominate on finer scales [55]. Applying PCNM analysis toward large-scale assessment of species-environment relationships is a well-established method [19,56,57]. Gilbert and Bennett [43] and Smith and Lundholm [28] criticized the application of variation partitioning to study the relationship between environmental variables and space, although they admitted that it yields useful results when carefully used. Our present analysis supports an optimistic view of this approach. All environmental patterns are spatially correlated on some scale [28], and all ecological processes are spatial to some extent [1]. The common fraction of variance explained jointly by environment and space appears to represent patterns generated by both environmental factors and the limitations on species dispersal [28]. In our study, the highest level of pure spatial variation was obtained for the epigeics + anecic assemblage (23.5\%), whereas the endogeics assemblage showed the lowest level (1.6\%, Table 6). Species, or even earthworm ecological categories, show specific dispersal behaviors [58], with endogeics typically showing less dispersal than do epigeic and anecic species.

We carefully selected the sampling scale and the spatial statistics tools to address the ecological question at hand [43]. We benefited from our previous knowledge regarding the biology and ecology of the species found in the region where the survey was undertaken [29,32,33,37,38]. Our study lays the groundwork for further detailed analysis of spatial structuring environmental factors and species assemblages on several scales, while also providing 
Table 3 Cross-correlograms of the root- and nutrient-related soil variables (significant Bonferroni corrected two-sided $p$-values $(0.05 / 11=0.0045)$ for each distance class were tested using 999 permutations under the null hypothesis)

\begin{tabular}{|c|c|c|c|c|c|c|c|c|c|c|c|c|c|}
\hline \multicolumn{2}{|l|}{ Variables } & \multicolumn{11}{|c|}{ Distance (number of pair points) } & \multirow{2}{*}{$\begin{array}{l}\text { Global } \\
\text { significance, } p^{\prime}\end{array}$} \\
\hline Plant below-ground $^{1}$ & Nutrient-related & $5.0(360)$ & $8.5(644)$ & $12.8(1112)$ & $17.5(1192)$ & $22.6(1548)$ & $27.5(1264)$ & $32.1(1128)$ & $36.9(1108)$ & $42.0(848)$ & $47.3(516)$ & $52.8(120)$ & \\
\hline \multirow[t]{9}{*}{ FiRL } & $\mathrm{N}_{0-5}$ & 0.090 & 0.028 & 0.021 & -0.022 & 0.026 & -0.011 & 0.005 & -0.036 & -0.004 & -0.069 & -0.133 & NS \\
\hline & $N_{5-10}$ & -0.015 & -0.042 & -0.036 & -0.034 & $0.046 *$ & 0.027 & 0.008 & -0.011 & 0.001 & 0.033 & -0.088 & NS \\
\hline & $\mathrm{SOC}_{0-5}$ & 0.063 & 0.039 & 0.027 & -0.022 & 0.012 & 0.011 & 0.014 & -0.043 & -0.009 & $-0.097 *$ & -0.076 & NS \\
\hline & $\mathrm{SOC}_{5-10}$ & 0.051 & $0.077 *$ & $0.082 * *$ & 0.039 & $0.065^{* *}$ & -0.027 & -0.044 & -0.092 ** & $-0.059 *$ & $-0.091 *$ & -0.128 & Significant \\
\hline & $P_{0-5}$ & 0.025 & 0.024 & $0.060 *$ & 0.016 & 0.033 & 0.007 & 0.010 & -0.032 & $-0.079 *$ & $-0.175 * *$ & -0.063 & Significant \\
\hline & $P_{5-10}$ & $-0.089 *$ & $-0.133 * *$ & $-0.060 *$ & -0.013 & 0.025 & $0.055 *$ & 0.028 & 0.038 & 0.001 & -0.002 & 0.044 & Significant \\
\hline & $C: \mathrm{N}_{0-5}$ & -0.061 & 0.030 & 0.010 & -0.001 & -0.034 & 0.043 & 0.025 & -0.011 & -0.010 & -0.045 & 0.122 & NS \\
\hline & $C: N_{5-10}$ & 0.053 & $0.099 *$ & $0.093 * *$ & 0.054 * & 0.020 & -0.043 & -0.040 & $-0.069 * *$ & -0.049 & $-0.101 * *$ & -0.034 & Significant \\
\hline & Litter & 0.081 & 0.066 & -0.020 & $-0.068 * *$ & -0.008 & -0.012 & 0.035 & $0.055 *$ & -0.019 & -0.053 & -0.022 & NS \\
\hline \multirow[t]{9}{*}{ CoRL } & $\mathrm{N}_{0-5}$ & -0.019 & 0.028 & 0.016 & 0.015 & -0.003 & 0.043 & 0.015 & 0.002 & -0.057 * & $-0.142 * *$ & 0.019 & Significant \\
\hline & $N_{5-10}$ & $-0.146 * *$ & -0.036 & -0.013 & -0.020 & -0.006 & 0.072 ** & 0.054 * & 0.030 & -0.006 & $-0.085^{*}$ & -0.009 & NS \\
\hline & $\mathrm{SOC}_{0-5}$ & -0.022 & 0.026 & 0.012 & 0.022 & 0.005 & 0.041 & 0.015 & -0.005 & -0.055 & $-0.139 * *$ & 0.026 & NS \\
\hline & $\mathrm{SOC}_{5-10}$ & -0.007 & 0.093 ** & 0.098 ** & 0.030 & 0.001 & 0.037 & -0.003 & $-0.084^{* *}$ & $-0.098 * *$ & $-0.121 * *$ & 0.004 & Significant \\
\hline & $P_{0-5}$ & 0.014 & 0.048 & -0.001 & 0.028 & $0.042 *$ & 0.033 & 0.005 & -0.030 & $-0.079 *$ & $-0.125 * *$ & -0.068 & NS \\
\hline & $P_{5-10}$ & $-0.127^{* *}$ & -0.122 ** & $-0.088 * *$ & -0.028 & 0.026 & 0.063 ** & $0.089 * * *$ & $0.076^{* *}$ & -0.003 & -0.042 & -0.039 & Significant \\
\hline & $C: N_{0-5}$ & -0.012 & -0.003 & -0.015 & 0.010 & 0.021 & -0.006 & 0.003 & -0.017 & 0.007 & 0.015 & 0.032 & NS \\
\hline & $C: N_{5-10}$ & 0.103 * & $0.104 *$ & $0.090 * * *$ & 0.041 & 0.005 & -0.023 & -0.045 & $-0.094^{* *}$ & -0.077 * & -0.033 & 0.007 & Significant \\
\hline & Litter & -0.036 & 0.005 & 0.010 & -0.014 & -0.002 & 0.012 & -0.016 & 0.031 & -0.020 & 0.035 & -0.081 & NS \\
\hline \multirow[t]{9}{*}{ FiRW } & $\mathrm{N}_{0-5}$ & 0.028 & -0.021 & -0.017 & $-0.062 *$ & 0.012 & 0.015 & 0.044 & -0.010 & 0.013 & -0.069 & 0.001 & NS \\
\hline & $\mathrm{N}_{5-10}$ & 0.062 & 0.010 & -0.009 & -0.006 & $0.062 * *$ & -0.013 & 0.005 & -0.047 & -0.038 & -0.052 & -0.061 & NS \\
\hline & $\mathrm{SOC}_{0-5}$ & -0.043 & -0.044 & -0.013 & $-0.059 *$ & -0.012 & 0.007 & $0.058 *$ & 0.014 & 0.059 * & -0.072 & 0.044 & NS \\
\hline & $\mathrm{SOC}_{5-10}$ & -0.075 & $-0.071 *$ & -0.036 & $-0.058 *$ & 0.022 & -0.018 & -0.021 & 0.012 & $0.109 * * *$ & 0.108 ** & 0.125 & Significant \\
\hline & $P_{0-5}$ & $0.103 *$ & $0.083 *$ & $0.099 * * *$ & 0.041 & 0.022 & 0.036 & 0.005 & $-0.092 * *$ & $-0.150 * *$ & $-0.243 * *$ & -0.157 & Significant \\
\hline & $P_{5-10}$ & $0.149 * * *$ & $0.145 * *$ & $0.094 * * *$ & 0.086 ** & $0.067^{* *}$ & 0.028 & -0.074 * & $-0.119 * *$ & $-0.192 * *$ & $-0.213 * *$ & $-0.203 *$ & Significant \\
\hline & $C: N_{0-5}$ & $-0.168 * *$ & -0.040 & 0.011 & 0.017 & $-0.053^{* *}$ & -0.025 & 0.025 & 0.051 & $0.105^{* *}$ & 0.004 & 0.068 & Significant \\
\hline & $C: N_{5-10}$ & $-0.111 *$ & -0.070 * & -0.023 & $-0.048 *$ & -0.027 & -0.005 & -0.020 & 0.045 & $0.122 * *$ & $0.132 * *$ & 0.154 & Significant \\
\hline & Litter & 0.060 & 0.054 & $-0.061 *$ & $-0.078 * *$ & -0.001 & -0.023 & 0.039 & 0.020 & 0.018 & 0.020 & $0.192 *$ & Significant \\
\hline \multirow[t]{3}{*}{ CoRW } & $\mathrm{N}_{0-5}$ & 0.005 & 0.013 & 0.027 & -0.023 & -0.007 & -0.003 & 0.020 & 0.025 & -0.018 & -0.084 * & 0.015 & NS \\
\hline & $N_{5-10}$ & -0.090 & -0.020 & 0.021 & $-0.049 *$ & -0.017 & 0.030 & 0.069 ** & 0.037 & 0.028 & $-0.110 * *$ & -0.014 & NS \\
\hline & $\mathrm{SOC}_{0-5}$ & 0.003 & 0.014 & 0.020 & -0.006 & 0.004 & -0.004 & 0.019 & 0.004 & -0.010 & $-0.092 *$ & 0.021 & NS \\
\hline
\end{tabular}


Table 3 Cross-correlograms of the root- and nutrient-related soil variables (significant Bonferroni corrected two-sided $\mathbf{p}$-values $(0.05 / 11=0.0045)$ for each distance class were tested using 999 permutations under the null hypothesis) (Continued)

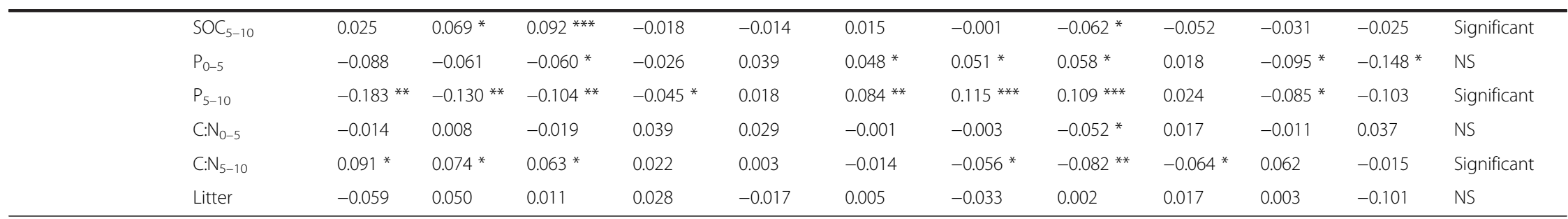

${ }^{1}$ FiRL, fine root length; CoRL, coarse root length; FiRW, fine root weight; CoRW, coarse root weight.

${ }^{*} p<0.05 ;{ }^{* *} p<0.01 ;{ }^{* * *} p<0.001$; NS, not significant.

The number of pair points (within brackets) and the lower and upper limits for each distance class employed while computing the cross-correlograms are indicated. 
Table 4 Cross-correlograms of the root- and soil physical variables (significant Bonferroni corrected two-sided $p$-values $(0.05 / 11=0.0045)$ for each distance class were tested using 999 permutations under the null hypothesis)

\begin{tabular}{|c|c|c|c|c|c|c|c|c|c|c|c|c|c|}
\hline \multicolumn{2}{|l|}{ Variables } & \multicolumn{11}{|c|}{ Distance (number of pair points) } & \multirow{2}{*}{$\frac{\text { Global }}{\text { significance, } p^{\prime}}$} \\
\hline Plant below-ground ${ }^{1}$ & Physical & $5.0(360)$ & $8.5(644)$ & $12.8(1112)$ & $17.5(1192)$ & $22.6(1548)$ & $27.5(1264)$ & $32.1(1128)$ & 36.9 (1108) & $42.0(848)$ & $47.3(516)$ & $52.8(120)$ & \\
\hline \multirow[t]{12}{*}{ FiRL } & Agg0.053-0.125 & $-0.121 *$ & 0.010 & $0.080 * *$ & -0.001 & 0.036 & -0.012 & $-0.061 *$ & -0.034 & 0.046 & -0.038 & 0.067 & NS \\
\hline & Agg0.125-0.25 & -0.005 & $0.103 * *$ & $0.106^{* * *}$ & 0.038 & 0.037 & $-0.059 *$ & $-0.096 * *$ & $-0.055^{*}$ & 0.030 & -0.069 & -0.112 & Significant \\
\hline & Agg0.25-0.5 & 0.010 & 0.060 & $0.099 * * *$ & $0.049 *$ & $0.043 *$ & -0.040 & $-0.068 * *$ & $-0.069^{* *}$ & 0.032 & $-0.131 * *$ & -0.058 & Significant \\
\hline & Agg0.5-1 & 0.043 & $0.125 * *$ & $0.106^{* * *}$ & $0.054 *$ & 0.029 & -0.057 & $-0.069 *$ & $-0.073 *$ & -0.008 & $-0.144 * *$ & -0.098 & Significant \\
\hline & Agg1-2 & 0.037 & $0.089 * *$ & $0.065 * *$ & $0.074 * *$ & 0.022 & $-0.063 * *$ & $-0.058 *$ & -0.037 & 0.013 & $-0.133 * *$ & -0.095 & Significant \\
\hline & Agg2-5 & $0.143 * *$ & $0.127 * *$ & $0.080 * *$ & $0.061 *$ & 0.016 & $-0.053 *$ & $-0.068 *$ & $-0.073^{* *}$ & -0.025 & $-0.096 *$ & -0.164 & Significant \\
\hline & Agg5-10 & -0.038 & -0.027 & $-0.104 * *$ & -0.008 & -0.030 & 0.031 & 0.023 & 0.031 & 0.028 & 0.025 & $0.243 * *$ & Significant \\
\hline & Agg $>10$ & $-0.107 *$ & $-0.127 * *$ & $-0.085^{* *}$ & $-0.057^{*}$ & -0.006 & 0.045 & $0.059 *$ & $0.074 *$ & -0.005 & $0.137 * *$ & 0.062 & Significant \\
\hline & $\mathrm{BD}$ & -0.022 & -0.045 & -0.025 & -0.015 & -0.002 & 0.011 & -0.001 & 0.028 & -0.015 & $0.090 *$ & 0.127 & NS \\
\hline & Comp & $-0.128 * *$ & -0.064 & -0.047 & 0.011 & 0.009 & 0.003 & 0.013 & 0.041 & -0.017 & $0.115 * *$ & $0.167 *$ & NS \\
\hline & Conduc & $0.149 * *$ & $0.123 * *$ & $0.076^{* *}$ & -0.002 & 0.003 & -0.044 & -0.031 & -0.034 & -0.029 & $-0.109 *$ & $-0.211 *$ & Significant \\
\hline & Hum & $-0.233^{* *}$ & $-0.125^{* *}$ & $-0.118 * *$ & -0.029 & 0.019 & 0.048 & $0.073 *$ & $0.078 * *$ & 0.003 & $0.102 *$ & $0.219 *$ & Significant \\
\hline \multirow[t]{12}{*}{ CoRL } & Agg0.053-0.125 & 0.025 & 0.016 & 0.040 & 0.038 & 0.019 & -0.052 & -0.022 & -0.054 & -0.020 & 0.034 & 0.030 & NS \\
\hline & Agg0.125-0.25 & $0.099 *$ & $0.121 * *$ & $0.092 * * *$ & $0.063 *$ & 0.003 & $-0.075 * *$ & $-0.056 *$ & $-0.094 * *$ & -0.058 & -0.006 & 0.035 & Significant \\
\hline & Agg0.25-0.5 & $0.087 *$ & $0.111 * *$ & $0.093 * *$ & $0.074 * *$ & -0.001 & $-0.049 *$ & -0.036 & $-0.108 * *$ & $-0.067 *$ & -0.037 & -0.086 & Significant \\
\hline & Agg0.5-1 & 0.123 & $0.173^{* * *}$ & $0.095^{* * *}$ & $0.071 * *$ & 0.006 & $-0.063 * *$ & $-0.061 *$ & $-0.114^{* *}$ & $-0.078 *$ & -0.035 & -0.052 & Significant \\
\hline & Agg1-2 & $0.085 *$ & $0.104 * *$ & $0.069 *$ & $0.046 *$ & 0.015 & -0.038 & -0.033 & $-0.070 *$ & $-0.090 *$ & -0.023 & -0.088 & Significant \\
\hline & Agg2-5 & $0.156^{* * *}$ & $0.173 * * *$ & $0.098 * * *$ & 0.058 & -0.003 & $-0.058 *$ & $-0.062 *$ & $-0.102^{* *}$ & $-0.081 *$ & -0.072 & 0.008 & Significant \\
\hline & Agg5-10 & -0.057 & 0.000 & $-0.080 * *$ & $-0.051 *$ & 0.007 & -0.035 & 0.029 & $0.060 *$ & $0.080 * *$ & 0.062 & 0.034 & Significant \\
\hline & Agg $>10$ & $-0.133 * *$ & $-0.174 * *$ & $-0.082 * *$ & $-0.070 * *$ & -0.013 & $0.067 *$ & $0.059 *$ & $0.119 * * *$ & $0.074 *$ & 0.048 & 0.055 & Significant \\
\hline & $\mathrm{BD}$ & -0.061 & -0.061 & $-0.053 *$ & -0.014 & 0.008 & 0.030 & 0.022 & 0.013 & 0.024 & $0.070 *$ & -0.068 & NS \\
\hline & Comp & -0.027 & -0.064 & -0.040 & -0.041 & -0.006 & 0.000 & 0.027 & 0.035 & 0.045 & $0.086 *$ & 0.044 & NS \\
\hline & Conduc & 0.068 & $0.149 * * *$ & $0.064 *$ & 0.031 & -0.005 & -0.015 & -0.038 & -0.049 & $-0.070 *$ & $-0.102 * *$ & -0.017 & Significant \\
\hline & Hum & $-0.123^{* *}$ & $-0.163^{* *}$ & $-0.114^{* *}$ & -0.030 & 0.018 & 0.011 & $0.087 * * *$ & $0.070 * *$ & $0.070 *$ & $0.088 *$ & 0.068 & Significant \\
\hline \multirow[t]{7}{*}{ FiRW } & Agg0.053-0.125 & $-0.099 *$ & 0.017 & $0.073 * *$ & 0.014 & 0.004 & -0.027 & -0.050 & -0.022 & 0.055 & 0.006 & 0.032 & NS \\
\hline & Agg0.125-0.25 & $-0.134 * *$ & -0.033 & -0.007 & -0.033 & -0.008 & $-0.055^{*}$ & -0.024 & 0.041 & $0.149 * * *$ & $0.100 * *$ & 0.070 & Significant \\
\hline & Agg0.25-0.5 & $-0.087 *$ & -0.043 & 0.001 & -0.041 & -0.001 & -0.030 & -0.010 & 0.015 & $0.144^{* * *}$ & 0.016 & 0.080 & Significant \\
\hline & Agg0.5-1 & -0.069 & -0.020 & 0.004 & $-0.051 *$ & -0.006 & -0.030 & 0.017 & 0.013 & $0.092 * * *$ & -0.008 & 0.100 & Significant \\
\hline & Agg1-2 & -0.073 & -0.018 & $-0.064 *$ & -0.048 & 0.001 & -0.014 & 0.032 & 0.043 & $0.107 * * *$ & -0.021 & 0.081 & Significant \\
\hline & Agg2-5 & $-0.098 *$ & $-0.082 *$ & $-0.080 * *$ & $-0.065 * *$ & -0.029 & -0.026 & 0.042 & $0.057 *$ & $0.174 * * *$ & $0.086 *$ & 0.093 & Significant \\
\hline & Agg5-10 & 0.019 & 0.048 & -0.027 & 0.034 & -0.021 & 0.041 & 0.009 & -0.040 & $-0.075 *$ & 0.004 & 0.055 & NS \\
\hline
\end{tabular}


Table 4 Cross-correlograms of the root- and soil physical variables (significant Bonferroni corrected two-sided $p$-values $(0.05 / 11=0.0045)$ for each distance class were tested using 999 permutations under the null hypothesis) (Continued)

\begin{tabular}{|c|c|c|c|c|c|c|c|c|c|c|c|c|c|}
\hline & Agg $>10$ & $0.091 *$ & 0.056 & 0.063 ** & $0.057 *$ & 0.036 & 0.022 & -0.039 & -0.047 * & $-0.155^{* *}$ & -0.084 * & -0.087 & Significant \\
\hline & $\mathrm{BD}$ & $0.090 *$ & $0.112 * *$ & 0.049 & $0.060 *$ & $0.049 *$ & 0.000 & $-0.098 * *$ & $-0.082 * *$ & $-0.119 * *$ & 0.033 & -0.015 & Significant \\
\hline & Comp & -0.072 & -0.011 & -0.014 & 0.011 & 0.016 & 0.020 & -0.044 * & 0.028 & -0.020 & $0.096 *$ & 0.006 & NS \\
\hline & Conduc & -0.016 & -0.055 & -0.042 & -0.036 & -0.052 * & 0.010 & $0.066 *$ & $0.048 *$ & $0.058 *$ & -0.023 & -0.003 & NS \\
\hline & Hum & -0.037 & -0.006 & 0.002 & 0.017 & 0.004 & 0.029 & -0.008 & 0.009 & $-0.068 *$ & 0.039 & -0.011 & NS \\
\hline \multirow[t]{12}{*}{ CORW } & Agg0.053-0.125 & 0.056 & 0.001 & 0.033 & 0.038 & 0.000 & $-0.069 * *$ & -0.012 & -0.042 & -0.017 & $0.079 *$ & 0.044 & NS \\
\hline & Agg0.125-0.25 & $0.135^{* *}$ & $0.112^{* *}$ & 0.076 ** & 0.042 & -0.020 & $-0.091 * *$ & -0.050 & $-0.087 * *$ & -0.042 & $0.076 *$ & 0.097 & Significant \\
\hline & Agg0.25-0.5 & $0.103 *$ & $0.081 *$ & $0.073 * *$ & 0.040 & -0.017 & $-0.076 * *$ & -0.019 & $-0.082 * *$ & -0.056 & 0.047 & 0.037 & NS \\
\hline & Agg0.5-1 & $0.120 * *$ & $0.113^{* *}$ & $0.070 * *$ & 0.049 & -0.025 & $-0.083 * *$ & -0.049 & -0.073 * & -0.019 & 0.041 & 0.029 & Significant \\
\hline & Agg1-2 & 0.088 & $0.103 * *$ & $0.052 *$ & 0.042 & -0.024 & $-0.056^{*}$ & -0.046 & -0.047 & -0.055 & 0.062 & 0.026 & Significant \\
\hline & Agg2-5 & $0.169 * * *$ & $0.165 * * *$ & 0.085 ** & $0.053 *$ & $-0.042 *$ & $-0.083 * *$ & $-0.080 * *$ & -0.076 ** & -0.036 & 0.012 & 0.122 & Significant \\
\hline & Agg5-10 & -0.052 & 0.038 & -0.045 & -0.008 & -0.017 & -0.004 & -0.010 & 0.044 & 0.080 * & -0.010 & -0.062 & NS \\
\hline & Agg $>10$ & $-0.140 * *$ & $-0.155^{* *}$ & $-0.081 * *$ & -0.054 * & 0.029 & $0.079 * *$ & $0.082 * * *$ & $0.090 * * *$ & 0.038 & -0.034 & -0.081 & Significant \\
\hline & $\mathrm{BD}$ & $-0.106 *$ & -0.096 * & $-0.058 *$ & 0.008 & 0.009 & 0.060 * & 0.033 & 0.035 & 0.001 & 0.018 & -0.109 & NS \\
\hline & Comp & 0.003 & -0.012 & -0.007 & -0.018 & -0.027 & 0.026 & 0.006 & 0.021 & -0.024 & 0.059 & 0.063 & NS \\
\hline & Conduc & 0.047 & $0.097 * *$ & $0.049 *$ & 0.026 & -0.026 & -0.029 & $-0.054 *$ & -0.024 & 0.007 & -0.054 & -0.009 & NS \\
\hline & Hum & $-0.102 *$ & $-0.084 *$ & -0.044 & -0.018 & 0.022 & 0.019 & $0.056 *$ & $0.052 *$ & -0.019 & 0.023 & 0.052 & NS \\
\hline
\end{tabular}

${ }^{1}$ FiRL, fine root length; CoRL, coarse root length; FiRW, fine root weight; CoRW, coarse root weight.

${ }^{*} \mathrm{p}<0.05 ;{ }^{* *} \mathrm{p}<0.01 ;{ }^{* * *} \mathrm{p}<0.001 ; \mathrm{NS}$, not significant.

The number of pair points (within brackets) and the lower and upper limits for each distance class employed while computing the cross-correlograms are indicated. 
Table 5 Significant positive/negative relationship between the spatial characteristics of earthworm species and the soil environmental variables measured in this study

\begin{tabular}{|c|c|c|c|c|c|c|c|c|c|c|c|c|}
\hline \multirow{3}{*}{$\begin{array}{l}\text { Earthworm community, species and } \\
\text { assemblages }\end{array}$} & \multicolumn{12}{|l|}{ Scales } \\
\hline & \multicolumn{4}{|c|}{ Medium >30 m } & \multicolumn{4}{|l|}{ Fine $10-20 \mathrm{~m}$} & \multicolumn{4}{|c|}{ Very fine $<10 \mathrm{~m}$} \\
\hline & Vars & Coeff & $P_{\text {init }}^{\S}$ & $P_{\text {corr }}$ & Vars & Coeff & $P_{\text {init }}$ & $P_{\text {corr }}$ & Vars & Coeff & $P_{\text {init }}$ & $P_{\text {corr }}$ \\
\hline \multirow[t]{4}{*}{ Community } & $P_{5-10}$ & Positive & * & NS & Litter & Negative & * & NS & $\mathrm{N}_{5-10}$ & Positive & $* * *$ & $* *$ \\
\hline & - & - & - & - & Comp & Positive & $*$ & NS & $C_{5-10}$ & Negative & $* *$ & * \\
\hline & - & - & - & - & - & - & - & - & $\mathrm{C}: \mathrm{N}_{5-10}$ & Positive & $* *$ & * \\
\hline & - & - & - & - & - & - & - & - & Humidity & Negative & * & NS \\
\hline \multirow[t]{7}{*}{ New genus 1} & $\mathrm{C}_{0-5}$ & Positive & $* * *$ & $* * *$ & $\mathrm{C}_{0-5}$ & Positive & $* * *$ & $* * *$ & Comp & Negative & $* *$ & * \\
\hline & $\mathrm{N}_{0-5}$ & Negative & $* * *$ & $* * *$ & $\mathrm{~N}_{0-5}$ & Negative & $* * *$ & $* * *$ & Humidity & Positive & $* *$ & * \\
\hline & $C: N_{0-5}$ & Negative & $* * *$ & $* *$ & $C: \mathrm{N}_{0-5}$ & Negative & $* * *$ & $* * *$ & - & - & - & - \\
\hline & Compaction & Negative & $* *$ & $* *$ & Compaction & Negative & $* *$ & $* *$ & - & - & - & - \\
\hline & Humidity & Positive & $* *$ & * & $C_{5-10}$ & Negative & $* *$ & * & - & - & - & - \\
\hline & $C_{5-10}$ & Negative & $* *$ & * & Litter & Negative & $* *$ & * & - & - & - & - \\
\hline & - & - & - & - & Humidity & Positive & $* *$ & * & - & - & - & - \\
\hline \multirow[t]{4}{*}{ Andiodrilus } & Ag0.25-2 & Positive & * & NS & - & - & - & - & - & - & - & - \\
\hline & Ag2 & Positive & * & NS & - & - & - & - & - & - & - & - \\
\hline & $>$ Ag5 & Positive & * & NS & - & - & - & - & - & - & - & - \\
\hline & $<$ Ag0.25 & Positive & * & NS & - & - & - & - & - & - & - & - \\
\hline Glossodrilus & - & - & - & - & Compaction & Positive & $*$ & NS & - & - & - & - \\
\hline \multirow[t]{8}{*}{ New genus 2} & - & - & - & - & $P_{0-5}$ & Positive & $* *$ & * & - & - & - & - \\
\hline & - & - & - & - & $\mathrm{Ag} 0.25 .2$ & Negative & * & NS & - & - & - & - \\
\hline & - & - & - & - & $\mathrm{Ag} 2$ & Negative & $*$ & NS & - & - & - & - \\
\hline & - & - & - & - & $>$ Ag5 & Negative & * & NS & - & - & - & - \\
\hline & - & - & - & - & $<\operatorname{Ag} 0.25$ & Negative & * & NS & - & - & - & - \\
\hline & - & - & - & - & Litter & Positive & * & NS & - & - & - & - \\
\hline & - & - & - & - & $N_{5-10}$ & Negative & * & NS & - & - & - & - \\
\hline & - & - & - & - & PR5 & Positive & * & NS & - & - & - & - \\
\hline \multirow[t]{3}{*}{ Aymara } & Compaction & Positive & $* *$ & NS & PR20 & Negative & * & NS & - & - & - & - \\
\hline & Humidity & Negative & $* *$ & NS & - & - & - & - & - & - & - & - \\
\hline & FiRL & Positive & * & NS & - & - & - & - & - & - & - & - \\
\hline \multirow[t]{2}{*}{ Martiodrilus } & Humidity & Positive & * & NS & $P_{5-10}$ & Positive & * & NS & - & - & - & - \\
\hline & FiRL & Negative & * & NS & & & & & & & & \\
\hline Endogeics & $P_{0-5}$ & Negative & $* * *$ & $* *$ & Litter & Negative & $*$ & NS & - & - & - & - \\
\hline \multirow[t]{3}{*}{ Epigeics + anecic } & Compaction & Negative & $* *$ & NS & PR20 & Negative & ** & NS & PR10 & Positive & * & NS \\
\hline & Litter & Positive & $* *$ & NS & $\mathrm{BD}$ & Negative & * & NS & - & - & - & - \\
\hline & Humidity & Positive & * & NS & PR5 & Positive & * & NS & - & - & - & - \\
\hline \multirow[t]{4}{*}{ Andiodrilus, Aymara and new genus 1} & Litter & Positive & $* *$ & NS & $\mathrm{BD}$ & Negative & ** & NS & Compaction & Negative & $* *$ & NS \\
\hline & Compaction & Negative & ** & NS & PR20 & Negative & * & NS & Humidity & Positive & $* *$ & NS \\
\hline & Humidity & Positive & * & NS & $P_{5-10}$ & Positive & * & NS & $\mathrm{C}_{0-5}$ & Positive & * & NS \\
\hline & - & - & - & - & $N_{5-10}$ & Negative & * & NS & $\mathrm{N}_{0-5}$ & Negative & * & NS \\
\hline \multirow[t]{4}{*}{ Martiodrilus, Glossodrilus and new genus 2} & $P_{0-5}$ & Positive & * & NS & - & - & - & - & - & - & - & - \\
\hline & Compaction & Negative & * & NS & - & - & - & - & - & - & - & - \\
\hline & CoRW & Negative & * & NS & - & - & - & - & - & - & - & - \\
\hline & Cond & Negative & * & NS & - & - & - & - & - & - & - & - \\
\hline
\end{tabular}

${ }^{5} \mathrm{~A}$ false discovery rate (FDR) procedure was applied to correct the initial $\mathrm{p}$-values (see text for explanation). ${ }^{*} \mathrm{p}<0.05 ;{ }^{* *} \mathrm{p}<0.01$; ${ }^{* *} \mathrm{p}<0.001$; NS, not significant. 
Table 6 Significant PCNM variables (spatial models with eigenfunctions associated with a positive Moran's I) for medium, fine and very fine spatial scales and results of the variation partitioning analysis using adjusted $R$ coefficients $\left(R_{a}{ }^{2}\right)$, i.e., the amount of variance explained by the environment, the spatial scales and residuals

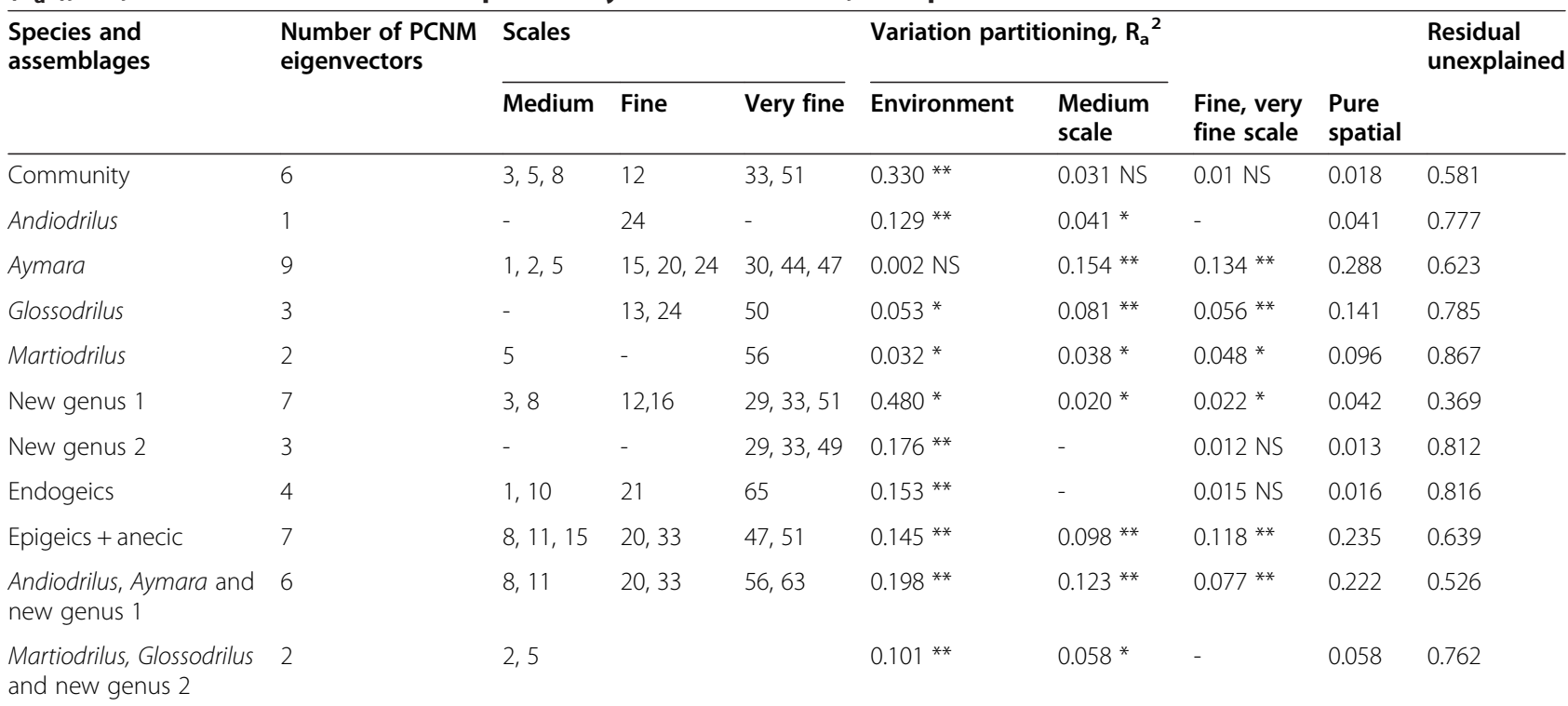

${ }^{*} p<0.05$; ${ }^{* *} p<0.01$; NS, not significant.

clues for developing an accurate and spatially explicit sampling design for earthworm communities. In addition, the utility of the tools used to select species assemblages and analyze their spatial attributes relative to the soil environmental variability was clearly demonstrated. We are confident that our results provide crucial insight into the spatial relationship between species assemblages and soil environmental variability on scales that range several tens of meters. The selection of assemblages from the correspondence analysis, in this case epigeics versus endogeics, and the statistical methods used to draw our conclusions provide insights that improve understanding regarding why particular species assemblages are found at particular sites. From an ecological point of view, our study not only suggests that specific environmental factors determine the structure and spatial distribution of earthworms in the gallery forest but also indicates that a large proportion of unexplained variation exists. Whether this variation is the result of unmeasured soil environmental variables or null model (random) patterns is a subject for further research.

\section{Conclusions}

Earthworms were spatially structured within a relatively small but highly heterogeneous plot; i.e., even at ranges of just a few meters, a multi-scale spatial pattern was observed. The amount of variation jointly explained by the environment and space was not high. However, these sources of variation should not be neglected because they represent unmeasured soil environmental factors and processes that limit species dispersal. Further studies are needed because dispersal traits, for example, remain largely unknown in many earthworm communities. In conclusion, specific abiotic factors were responsible for the observed patterns, and the importance of these patterns needs to be elucidated, even if the multi-scale approach carries additional difficulties and caveats when interpreting the results.

\section{Methods}

Study area

Sampling was conducted in a gallery forest (GF) at the CORPOICA-CIAT Carimagua field research station in the Eastern Plains of Colombia ( $4^{\circ} 37^{\prime} \mathrm{N}, 71^{\circ} 19^{\prime} \mathrm{W}, 170 \mathrm{~m}$ a.s.l.). The study area is a well-drained savanna forming a young alluvial plain consisting of Pleistocene and Holocene sediments of Andean origin. The terrain is characterized by open herbaceous savannas where GFs follow a dense braided drainage network of rivers toward the Orinoco catchment. The yearly average temperature and precipitation are $26^{\circ} \mathrm{C}$ (iso-hyperthermy) and 2,200 $\mathrm{mm}$, respectively, with clayey Oxisols of low $\mathrm{pH}$ (4.2-4.4 in water) and fertility, with low available P (1-2 ppm Bray II) and Al saturation $>90 \%$ (CIAT data).

The plant community of the GF is characterized by several tree species, including Dendropanax arboreus (L.) Decne. \& Planch. (1854) (Araliaceae), Enterolobium spp. (Leguminosae), Ficus spp. (Moraceae), Jacaranda copaia (Aubl.) (Bignoniaceae), Copernicia tectorum (Kunth) Mart. (Caesalpiniaceae), and Cecropia sp. (Cecropiaceae). Other species include Mauritia flexuosa L.f. and Mauritiella (Palmaceae), Attalea maripa (Palmaceae), Nectandra membranacea (Sw.) Griseb. (Lauraceae), Didymopanax morototoni (Aubl.) Decne. \& Planch. 
(Araliaceae), Virola sp. (Myristicaceae), and Hymenaea courbaril L. (Caesalpiniaceae) [59].

\section{Earthworms and soil sampling}

Earthworms and soil samples were collected at 100 sampling points evenly distributed within a $45 \times 45 \mathrm{~m}^{2}$ grid with $5 \mathrm{~m}$ of inter-sample distance (Figure 5). The earthworms were identified, and their abundance was counted in situ from soil blocks of $25 \times 25 \mathrm{~cm} 2$ and a depth of $20 \mathrm{~cm}$ [60]. Previously, the fresh, tower-like casts deposited on the soil surface by Martiodrilus sp. (anecic) were counted at each point within $1 \mathrm{~m}^{2}$ quadrats, as they are reliable indicators of the number of active individuals [61].

In total, 400 soil samples were collected for physical and chemical analyses. Soil cores were collected along the four sides of each sampling point (Figure 5). The core method $(5 \mathrm{~cm}$ depth and $5 \mathrm{~cm}$ diam. metal cylinder) was used for bulk density (soil dry mass per volume) following [62]. Water content (soil water per volume and soil water per dry mass) was determined gravimetrically, and hydric conductivity and susceptibility to compaction were also measured [63].

A second core $(10 \mathrm{~cm}$ depth and $5 \mathrm{~cm}$ diam. metal cylinder) was used for soil organic carbon (SOC), nitrogen $(\mathrm{N})$ and phosphorous $(\mathrm{P})$ measurements at $0-5$ and 5$10 \mathrm{~cm}$. The soil was then oven dried at $75^{\circ} \mathrm{C}$ for $48 \mathrm{~h}$ and finely ground $(<200 \mu \mathrm{m})$. A standard colorimetric method was used after digestion in $\mathrm{H}_{2} \mathrm{SO}_{4}$ to measure SOC, and the Kjeldahl method was used to assess the total N. Available P was determined using the Bray-II extraction method. $\mathrm{C}: \mathrm{N}$ and $\mathrm{C}: \mathrm{P}$ ratios were calculated as the SOC concentration divided by the total $\mathrm{N}$ and $\mathrm{P}$ concentrations, respectively.

Another soil core $(15 \mathrm{~cm}$ depth and $10 \mathrm{~cm}$ diam.) was taken to assess the size-class aggregate distribution; ca. $100 \mathrm{~g}$ of air-dried soil was mechanically shaken in a sieve column of 4.75, 2, 1, 0.5 and $0.250 \mathrm{~mm}$ for $30 \mathrm{~min}$. The last soil core $(15 \mathrm{~cm}$ depth and $10 \mathrm{~cm}$ diam.) was used for root length and biomass quantification. Soil was washed in the lab and sieved to separate the fine $(<2 \mathrm{~mm})$ and coarse roots $(>2 \mathrm{~mm})$ and then oven dried at $105^{\circ} \mathrm{C}$ for $48 \mathrm{~h}$.

Resistance to penetration (RP) was measured (3 replicates) using a hand penetrometer at each sampling point. The soil moisture content (volumetric) of the topsoil at the time of sampling was ca. $38 \%(\mathrm{pF}=2.8)$.

\section{Multivariate ordination analysis (CA)}

Species abundance (raw data) was analyzed using correspondence analysis (CA). When the species abundance was $<5 \%$ of the total, it was removed from the species matrix. The extracted factorial axes allowed us to identify various species assemblages, i.e. these were defined according to the sum of the individuals of all species linked to positive or negative row scores of the three axes.

\section{Species assemblage patches and gaps}

SADIE (Spatial Analysis Distance IndicEs) analysis [64,65] was used to assess the presence of significant patches and gaps within species assemblages. The index uses count data, i.e., the total number of individuals who corresponded to any of the assemblages identified per sampling point. A global index of aggregation $\left(I_{a}\right)$ is computed:

$$
\mathrm{I}_{\mathrm{a}}=\mathrm{D} / \mathrm{Ea},
$$

where $\mathrm{D}$ is the distance moved to achieve the regular pattern for the observed data and $\mathrm{Ea}$ is the arithmetic mean distance to regularity for non-regular randomized samples [64].

$I_{a}$ equals 1 for a random distribution, whereas it is $>1$ or $<1$ for either a clumped (aggregated) or regular spatial pattern, respectively [65].

SADIE identifies clusters of high (patches) and low (gaps) mean density, respectively, and these clusters are categorized as $v_{i}$ (positive) and $v_{j}$ (negative cluster index). A patch or gap comprises at least one sample location where the cluster index $\left(\mathrm{v}_{\mathrm{i}}\right.$ or $\left.\mathrm{v}_{\mathrm{j}}\right)$ is significant at the heuristic threshold of 1.5 and -1.5 , respectively. Adjacent sample locations with significant index values form a single cluster [65]. The observed $v_{i}$ or $v_{j}$ indices are tested using random permutations against the $\mathrm{H}_{0}$ of complete spatial independence of counts [66].

In this study, we used positive and negative row scores extracted from the CA to obtain count data and compute the SADIE $v_{i}$ and $v_{j}$ cluster indices. Factorial coordinates have been used as a typical procedure to analyze the inner structures of data matrices for community analysis $[29,33,37-39,67,68]$. Because the row scores and factorial coordinates are not count data, which is a requisite for applying SADIE statistics, the various assemblages were obtained by summing the earthworm count data linked to the positive and negative row scores along the CA axes.

Finally, a spatial association/dissociation index was computed between species assemblage pairs [66]. The local association indices calculated from their individual samplingunit clustering indices are correlated between species assemblage pairs. The observed value of the association index is tested against the $\mathrm{H}_{0}$ of complete spatial independence of the counts (based on random permutations). The two-tailed associated probability levels at $\alpha=5 \%$ are $<0.025$ and $>0.975$ for significant association and dissociation, respectively [66].

\section{Spatial autocorrelation analysis}

In the presence of a spatial dependence, the observation made at one location is more similar to observations 


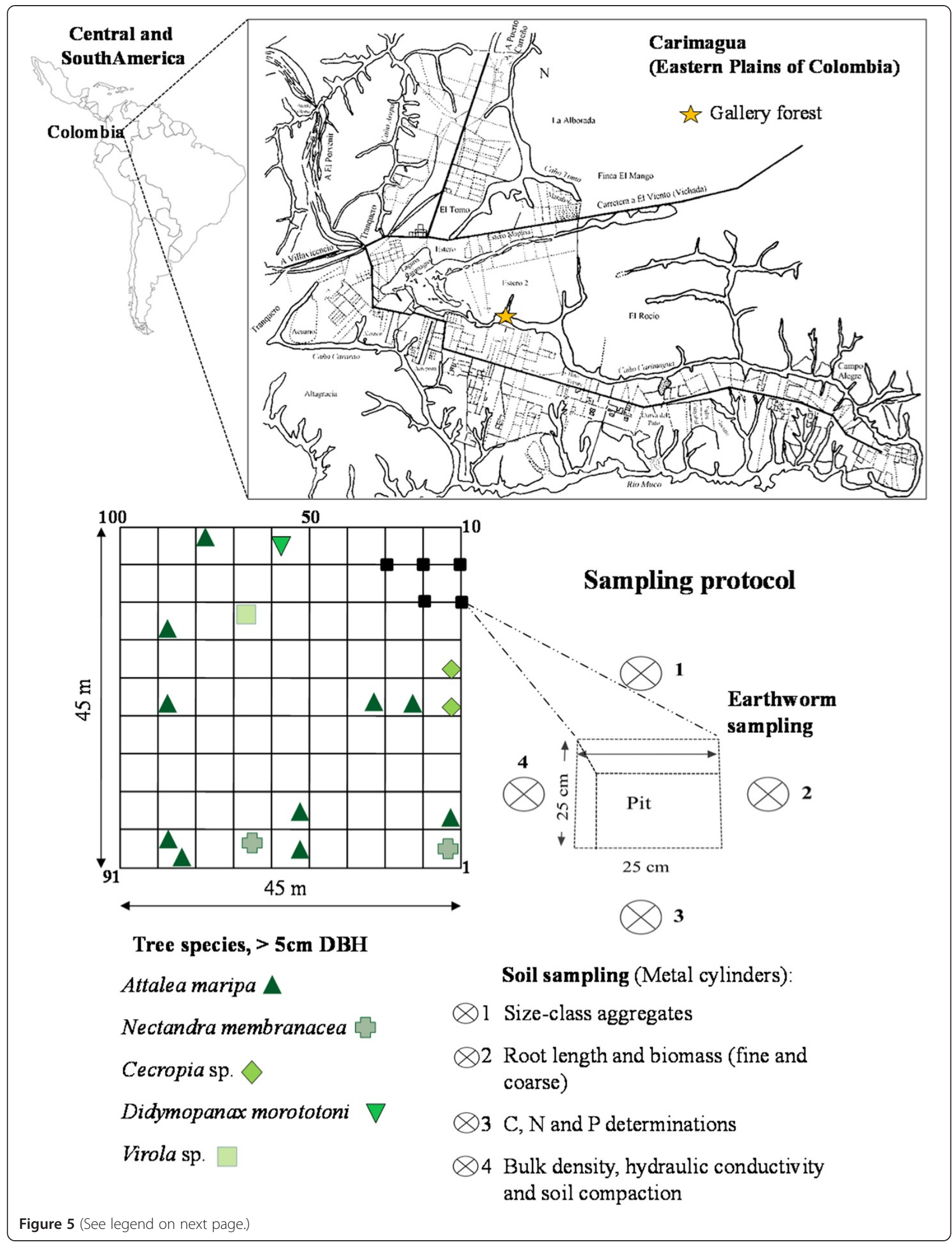


(See figure on previous page.)

Figure 5 Sampling protocol used with a regular grid of $10 \times 10$ sampling points and a $\mathbf{5}$ inter-sample distance. A total of 400 soil samples were collected for the various soil analyses and 100 soil monoliths for earthworm species counts. The location of tree species (>5 $\mathrm{m}$ diameter at breast height, DBH) within the surveyed 0.2 ha plot are shown together with the soil pit where the earthworms were sampled, identified and counted, as well as the four soil cores taken for physical and chemical determinations from each of the 100 sampling points

made at nearby sites [2], breaking the rule of sample independence for statistical analyses [23]. To assess the degree of spatial autocorrelation, the (semi)-variogram is a function that describes the spatial pattern of any variable with increasing inter-sample (lag) distance. When positive autocorrelation exists, the semi-variance $\gamma(\mathrm{h})$ increases until it reaches a maximum value (the "sill") for a given lag distance, which is referred to as the range. This parameter defines the limit of spatial dependence of the variable concerned (detailed in $[22,69]$ ). Estimated values of $\gamma(\mathrm{h})$ are adjusted using a theoretical model $[70,71]$ that is later applied with an interpolation technique called "kriging" to estimate values of the variable under study at non-sampled sites [22]. In our study, interpolated maps were used for root-related variables using only the modeled parameters obtained in the variogram [33].

Cross-variograms can be calculated to assess how two variables co-vary in space [72]. Similar to univariate variograms, cross-covariances may be computed using the values of two distinct variables observed at locations separated by lag h [73]. However, variograms and crossvariograms are not associated with formal testing for departures from randomness (an $\mathrm{r}^{2}$ correlation coefficient could be used to adjust the curve). However, in our study, spatial cross-correlation among the root-related variables, soil nutrient contents and physical variables was assessed by calculating the spatial cross-correlogram $[55,74]$. A spatial autocorrelation coefficient, named Moran's I, is plotted in the correlogram for increasing distance classes [75]. Data were allocated to 11 distance classes with a minimum of 50 pairs of points for each distance class to compute the cross-correlogram. The significance of the correlogram is tested with a Monte Carlo simulation [20]; it is significant when at least one coefficient is lower than the Bonferroni corrected p' of $\alpha^{\prime}=\alpha / \mathrm{k}$ for the $\mathrm{k}$ distance classes used [76]. Data normality was tested with a Kolmogorov-Smirnov test; when the normality assumption was not confirmed, a Box-Cox transformation was used [77]. The gstat and ncf packages of the $\mathrm{R}$ program 2.15.1 [78] were used to compute the variograms and cross-correlograms and to depict the kriged maps.

\section{Principal coordinates of neighbor matrices (PCNM) and variation partitioning}

The multi-scale spatial analysis of fauna data and soil environmental variability was performed using PCNM analysis [24,79]. This method allows to capture extremely complex structures [80] and is based on the principal coordinate analysis ( $\mathrm{PCoA}$ ) of a truncated pairwise geographic distance matrix between sampling sites [25]. It creates PCNM variables (spatial predictors or eigenfunctions) and a spectral decomposition of spatial relationships from broad to fine spatial scales [81] that is encompassed by the data matrix among sampled sites and then determines to which PCNM variables the response data (uni- or multivariate) respond statistically [79]. Only spatial eigenfunctions associated with positive eigenvalues based on Moran's I were used to define the spatial structures [3], which represents a highly conservative method due to its penalization of degrees of freedom and adjusted $\mathrm{R}^{2}$ statistics [43].

The PCNM variables that significantly contribute toward explaining the species response data are grouped into a small number of submodels, whereas they are normally assigned to broad, intermediate, and fine scales. The predicted values generated for each submodel can then be reanalyzed using canonical analysis against environmental variables to identify the environmental variables associated with species distributions on the scale represented by each submodel [25]. The forward-selection procedure was used [82] to reduce Type I error, as it is known to underestimate the residual variance [83]. In other words, the probability of selecting at least one PCNM is greater than the chosen significance level, even if the response variable is not spatially structured [80]. Appropriate and rigorous approaches for submodel selection have been argued by [43] and [81] is support of improving the methodological developments in MEM-based methods. Scale is generally defined according to the main features of the sampling design, such as the extent of the study area or the size and spacing of the sampling units [84]. Given the dimensions of the plot $(45 \times 45 \mathrm{~m})$ and our knowledge on the spatial distribution of various earthworm species in the area $[33,37,38]$, the scales were grouped for convenience into medium $(>30 \mathrm{~m})$, fine $(10-20 \mathrm{~m})$ and very fine $(<10 \mathrm{~m})$.

The next step is to relate the spatial components using significant Bonferroni-adjusted $\mathrm{p}$ values extracted from the species matrix with soil variables. In other words, species-soil environment regression analysis is performed independently on each scale identified by the PCNM variables. Variogram analysis for each PCNM variable is performed to identify the spatial scale at 
which the relationship was significant. The lowest value of the Akaike information criterion (AIC) identifies the best spatial model.

Partitioning the variation of a species response data table among two or more explanatory tables is performed using multivariate variation partitioning [85], which determines how much of the species variation is spatially structured and associated with the measured environmental variables $[57,80]$. The variation partitioning analysis is based on the adjusted $R^{2}$ statistic $R_{a}{ }^{2}$ [86], and patterns on finer scales identified by the PCNM variables appear smoother compared to other spatially explicit models, such as nested variograms and filter kriging [79].

The data matrix included count data for 6 earthworm species, 23 soil environmental variables (Additional files 3 and 4) and xy coordinates for 100 sampling points. It has been recommended that fauna data should be detrended and transformed during PCNM analysis. Contrary to correspondence analysis, earthworm abundance data were Hellinger transformed because PCNM has been found to be inappropriate for raw data that includes many null abundances [87]. Earthworm spatial distribution is represented by patches, and clearly meaningful trends are rarely observed; consequently, the data were not detrended. In other words, we were cautious with the use of tests to determine the presence of trends because they are likely not appropriate for patchy patterns. The packages vegan, mass and packfor were used for all the calculations needed during PCNM analysis in R 2.15.1 [78].

\section{Adjustment of the probability level}

The $\alpha<0.05$ probability level was corrected using the false discovery rate (FDR) procedure for multiple comparisons [88], in which the power of multiple tests is optimized while controlling for the proportion of significant results that might be Type I errors. The $\mathrm{p}$ values from the individual tests are used to perform the corrections and search for significant differences at the corrected probability level. The comparison starts with the highest $\mathrm{p}$ value obtained from the individual tests, then each value is checked until encountering the first value that meets the requirement, i.e., the highest $\mathrm{p}$ value that is smaller than the corrected $\mathrm{p}$ [89]. The transformations include the following:

$\mathrm{p}(\mathrm{i}) \leq(\alpha / \mathrm{m})^{*} \mathrm{i}$, where $\mathrm{m}$ is the number of tests (variables) and $i$ is the test (variable) ranked in ascending order, i.e., $\mathrm{p}(1) \leq \ldots . \leq \mathrm{p}(\mathrm{m})$. The final $\mathrm{p}$ value corresponded to the following correction:

$$
p_{\text {corr }}=(0.05 \times \text { number of variables }) / \text { ranked } p(\text { maximum })
$$

During PCNM analysis, three tests were performed that corresponded to the three spatial scales used: the medium, fine and very fine scales.

\section{Additional files}

\begin{abstract}
Additional file 1: Plot at the grid nodes of the PCNM variables selected to model earthworm distribution. A square size is proportional to the value associated to positive (black squares) and negative (white squares) spatial autocorrelation with medium- to fine- and very fine-scale spatial models. Lower order vectors represent broad-scale groupings, and higher order vectors represent more fine-scale groupings. These eigenvectors represent a multi-scale metric for grouping sites, and thus do not represent any computed soil parameter that was measured at sampling sites. The size of the symbols is proportional to the PCNM variables.

Additional file 2: Map of the fitted scores of the significant canonical axes in the PCNM analysis for species (A) and species assemblages and the whole community (B). The size of squares is proportional to its associated value; black and white colors indicate positive and negative signs of the value associated to the square, respectively.

Additional file 3: Raw count data of species in each sampling point and the resulting assemblages obtained from the positive and negative row scores of the three axes extracted in the correspondence analysis. These data were later use to calculate SADIE $v_{i}$ and $v_{j}$ cluster indexes.

Additional file 4: Summary statistics of soil environmental variables analysed in this study.
\end{abstract}

\section{Competing interests}

The authors declare and confirm that they have no competing financial or non-financial interests associated with this manuscript.

\section{Authors' contributions}

JJJ designed the experimental sampling layout and conducted the fieldwork. $J J J$ and JP performed statistical analysis and wrote the main body of the paper. TD and PL contributed to the writing. All authors read and approved the final manuscript.

\section{Acknowledgements}

This study was financed by the DIVERSITAS program and CIAT (Soils Unit) We are particularly grateful for the useful comments provided by R. J.

Thomas and I. Rao and for the continuous support of soil ecology studies by E. Amézquita. We also gratefully acknowledge the help provided by field and lab research assistants at CIAT. We thank Dr. J. Perry at Rothamsted for kindly providing SADIE software and the ARAID foundation for support to the first author. We acknowledge support of the publication fee by the CSIC Open Access Publication Support Initiative through its Unit of Information Resources for Research (URICI). Finally, we are grateful for the insightful comments and valuable suggestions provided by two reviewers, which improved an early version of the manuscript.

\section{Author details}

${ }^{1}$ Department of Biodiversity Conservation and Ecosystem Restoration, Pyrenean Institute of Ecology (IPE), Spanish National Research Council (CSIC), Jaca (Huesca) ES-22700, Spain. ${ }^{2}$ Centre d'Ecologie Fonctionnelle et Evolutive, UMR 5175 CNRS, 1919 Route de Mende, 34293 Montpellier Cedex 5, France. ${ }^{3}$ Université Pierre et Marie Curie (Paris 6), 4 place Jussieu, 75005 Paris, France. ${ }^{4}$ INRA, UMR CBGP (INRA/IRD/Cirad/Montpellier SupAgro), Campus International de Baillarguet, CS 30016, F-34988 Montferrier-sur-Lez cedex, France.

Received: 26 August 2014 Accepted: 26 September 2014

Published online: 05 December 2014

\section{References}

1. Allen TFH, Hoekstra TW: Toward a Unified Ecology. New York: Columbia University Press; 1992.

2. Legendre P: Spatial autocorrelation: trouble or new paradigm? Ecol 1993, 74(6):1659-1673.

3. Dray S, Legendre P, Peres-Neto PR: Spatial modelling: a comprehensive framework for principal coordinate analysis of neighbour matrices (PCNM). Ecol Model 2006, 196:483-493. 
4. Hutchinson GE: Concluding remarks. In Cold Spring Harbor Symposium: 1957; Cold Spring Harbor. New Haven, Connecticut: Quant. Biology; 1957:415-427.

5. Schoener TW: Resource partitioning in ecological communities. Sci 1974, 185(4145):27-39.

6. Connell $\mathrm{JH}$ : On the prevalence and relative importance of interspecific competition: evidence from field experiments. Am Nat 1983. 122(5):661-696.

7. Goldberg DE, Barton AM: Patterns and consequences of interspecific competition in natural communities: a review of field experiments with plants. Am Nat 1992, 139(4):771-801.

8. Wilson JB, Habiba G: Limitation to species coexistence: evidence for competition from field observations, using a patch model. J Veg Sci 1995, 6:369-376.

9. Belyea $L R$, Lancaster J: Assembly rules within a contingent ecology. Oikos 1999, 86(3):402-416.

10. Gotelli NJ, Ellison AM: Assembly rules for New England ant assemblages. Oikos 2002, 99(3):591-599.

11. Ellwood MDF, Manica A, Foster WA: Stochastic and deterministic processes jointly structure tropical arthropod communities. Ecol Lett 2009, 12:277-284.

12. Drake JA: Communities as assembled structures: do rules govern pattern? TREE 1990, 5:159-164.

13. Weslien J, Djupström LB, Schroeder M, Widenfalk O: Long-term priority effects among insects and fungi colonizing decaying wood. J Anim Ecol 2011, 80:1155-1162.

14. Fukami T, Dickie IA, Wilkie P, Paulus BC, Park D, Roberts A, Buchanan PK, Allen RB: Assembly history dictates ecosystem functioning: evidence from wood decomposer communities. Ecol Lett 2010, 13:675-684.

15. Gravel D, Canham CD, Beaudet M, Messier C: Reconciling niche and neutrality: the continuum hypothesis. Ecol Lett 2006, 9:399-409.

16. Rossi JP, van Halder I: Towards indicators of butterfly biodiversity based on a multiscale landscape description. Ecol Indic 2010, 10(2):452-458.

17. Beale CM, Lennon JJ, Yearsley JM, Brewer MJ, Elston D: Regression analysis of spatial data. Ecol Letters 2010, 13:246-264.

18. Lennon JJ: Red-shifts and Red herrings in geographical ecology. Ecography 2000, 23:101-113.

19. Blanchet FG, Bergeron JAC, Spence JR, He F: Landscape effects of disturbance, habitat heterogeneity and spatial autocorrelation for a ground beetle (Carabidae) assemblage in mature boreal forest. Ecography 2013, 36:636-647.

20. Fortin MJ, Dale MRT: Spatial Analysis. A Guide for Ecologists. Cambridge: Cambridge University Press; 2005

21. Legendre $P$, De Cáceres $M$ : Beta diversity as the variance of community data: dissimilarity coefficients and partitioning. Ecol Lett 2013, 16:951-963.

22. Goovaerts P: Geostatistics for Natural Resources Evaluation. Oxford: Oxford University Press; 1997.

23. Rossi J-P, Lavelle P, Tondoh JE: Statistical tool for soil biology X. Geostatistical analysis. Eur J Soil Bio/ 1995, 31(4):173-181.

24. Borcard D, Legendre P: All-scale spatial analysis of ecological data by means of principal coordinates of neighbour matrices. Ecol Model 2002, 153:51-68.

25. Borcard D, Legendre $P$, Avois-Jacquet $C$, Tuomisto H: Dissecting the spatial structure of ecological data at multiple scales. Ecology 2004, 85(7):1826-1832

26. Griffith DA, Peres-Neto PR: Spatial modelling in Ecology: the flexibility of the eigenfunction spatial analyses. Ecol 2006, 87:2603-2613.

27. Currie DJ: Disentangling the roles of environment and space in ecology. J Biogeogr 2007, 34:2009-2011.

28. Smith TW, Lundholm JT: Variation partitioning as a tool to distinguish between niche and neutral processes. Ecography 2010, 33:648-655.

29. Decaëns T, Jiménez JJ, Rossi J-P: A null-model analysis of the spatio-temporal distribution of earthworm species assemblages in Colombian grasslands. J Trop Ecol 2009, 25(4):415-427.

30. Ryti RT, Case TJ: Spatial arrangement and diet overlap between colonies of desert ants. Oecologia 1984, 62:401-404.

31. Ward DF, Beggs JR: Coexistence, habitat patterns and the assembly of ant communities in the Yasawa islands, Fiji. Acta Oecol 2007, 32:215-223.

32. Jiménez JJ, Decaëns T, Rossi J-P: Soil environmental heterogeneity allows spatial co-occurrence of competitor earthworm species in a gallery forest of the Colombian "Llanos". Oikos 2012, 121:915-926.

33. Jiménez JJ, Decaëns T, Amézquita E, Rao I, Thomas RJ, Lavelle P: Short-range spatial variability of soil physico-chemical variables related to earthworm clustering in a Neotropical gallery forest. Soil Biol Biochem 2011, 43:1071-1080.

34. Amarasekare P: Competitive coexistence in spatially structured environments: a synthesis. Ecol Lett 2003, 6:1109-1122.

35. Ettema $\mathrm{CH}$, Yeates GW: Nested spatial biodiversity patterns of nematode genera in a New Zealand forest and pasture soil. Soil Biol Biochem 2003, 35(2):339-342

36. Rossi J-P, Delaville $L$, Quénéhervé $P$ : Microspatial structure of a plant- parasitic nematode community in a sugarcane field in Martinique. App/ Soil Ecol 1996, 3:17-26.

37. Decaëns T, Rossi J-P: Spatio-temporal structure of earthworm community and soil heterogeneity in a tropical pasture. Ecography 2001, 24(6):671-682.

38. Jiménez JJ, Decaëns T, Rossi JP: Stability of the spatio-temporal distribution and niche overlap in neotropical earthworm assemblages. Acta Oecol 2006 30(3):299-311.

39. Rossi JP: Clusters in earthworm spatial distribution. Pedobiologia 2003, 47(5-6):490-496.

40. Rossi J-P, Quénéhervé P: Relating species density to environmental variables in presence of spatial autocorrelation: a study case on soil nematodes distribution. Ecography 1998, 21(2):117-123.

41. Jimenez JJ, Rossi JP, Lavelle P: Spatial distribution of earthworms in acid-soil savannas of the eastern plains of Colombia. App/ Soil Ecol 2001 17(3):267-278

42. Whalen JK: Spatial and temporal distribution of earthworm patches in corn field, hayfield and forest systems of southwestern Quebec, Canada. Appl Soil Ecol 2004, 27(2):143-151.

43. Gilbert B, Bennet JR: Partitioning the variation in ecological communities: does the numbers add up? J Appl Ecol 2010, 47:1071-1082.

44. Wardle DA, Lavelle P, Cadisch G, Giller KE: Linkages between soil biota, plant litter quality and decomposition. In Driven by Nature: Plant Litter Quality and Decomposition. Wallingford, Oxon, UK: CAB International; 1997:107-124.

45. Lavelle P: Stratégies de reproduction chez les vers de terre. Acta Oecol 1981, 2(2):117-133.

46. Bouché MB: Lombriciens de France. Ecologie et systématique. Paris: I.N.R.A; 1972.

47. Lavelle P: Faunal activities and soil processes: adaptive strategies that determine ecosystem function. Adv Ecol Res 1997, 27:93-132.

48. Van Teeffelen AJA, Ovaskainen O: Can the cause of aggregation be inferred from species distributions? Oikos 2007, 116(1):4-16.

49. Ettema CH, Wardle DA: Spatial soil ecology. Trends Ecol Evol 2002, 17(4):177-183.

50. Wardle DA: Communities and Ecosystems - Linking the Aboveground and Belowground Components. Princeton: Princeton university Press; 2002.

51. Boettcher SE, Kalisz PJ: Single-tree influences on soil properties in the mountains of eastern Kentucky. Ecol 1990, 71:1365-1372.

52. Rhoades CC: Single-tree influences on soil properties in agroforestry: lessons from natural forest and savanna ecosystems. Agrofor Syst 1997 35:71-94.

53. Pickett STA, Kolasa J, Jones CG: Ecological Understanding, the Nature of Theory and the Theory of Nature. 2nd edition. Burlington, MA: Academic Press; 2007.

54. Díez JM, Pulliam HR: Hierarchical analysis of species distributions and abundance across environmental gradients. Ecol 2007, 88(12):3144-3152.

55. Legendre $\mathrm{P}$, Fortin $\mathrm{M}$-J: Spatial pattern and ecological analysis. Vegetatio 1989, 80:107-138.

56. García D, Zamora R, Amico GC: The spatial scale of plant-animal interactions: effects of resource availability and habitat structure. Ecol Monogr 2010, 81(1):103-121.

57. Legendre $P$, Xiangcheng $M$, Haibao $R$, Keping M, Mingjian $Y$, I-Fang S, Fangliang $\mathrm{H}$ : Partitioning beta diversity in a subtropical broad-leaved forest of China. Ecol 2009, 90:663-674.

58. Mathieu J, Barot S, Blouin M, Caro G, Decaëns T, Dubs F, Dupont L, Jouquet $P$, Nai P: Habitat quality, conspecific density, and habitat pre-use affect the dispersal behaviour of two earthworm species, Aporrectodea icterica and Dendrobaena veneta, in a mesocosm experiment. Soil Biol Biochem 2010, 42:203-209.

59. Ramia M: Plantas de las Sabanas Llaneras. Caracas: Monte Ávila Eds; 1974

60. Anderson JM, Ingram JSI: In Tropical Soil Biology and Fertility. A Handbook of Methods. Edited by Anderson JM, Ingram JSI. Wallingford, UK: CAB International; 1993:221.

61. Jiménez JJ, Moreno AG, Decaëns T, Lavelle P, Fisher MJ, Thomas RJ: Earthworm communities in native savannas and man-made pastures of the Eastern Plains of Colombia. 1998 
62. Blake GR, Hartge KH: Bulk density. In Methods of Soil Analysis. 1986:363-375.

63. Klute A: Water retention: Laboratory methods. In Methods of Soil Analysis Part 1 Physical and Mineralogical Methods, Agron. Monogr. 9. Edited by Klute A. Madison, WI: ASA and SSSA; 1986:635-662.

64. Perry JN: Measures of spatial pattern for counts. Ecol 1998, 79:1008-1017.

65. Perry JN, Winder L, Holland JM, Alston RD: Red-blue plots for detecting clusters in count data. Ecol Lett 1999, 2:106-113.

66. Perry JN, Dixon P: A new method for measuring spatial association in ecological count data. Ecoscience 2002, 9:133-141.

67. Rossi JP: Short-range structures in earthworm spatial distribution. Pedobiologia 2003, 47(5-6):582-587.

68. Decaëns T, Margerie P, Renault J, Bureau F, Aubert M, Hedde M: Niche overlap and species assemblage dynamics in an ageing pasture gradient in north-western France. Acta Oecol 2011, 37:212-219.

69. Cressi NAC: Statistics for Spatial Data. New York: John Wiley \& Sons; 1993.

70. McBratney $A B$, Webster $R$ : Choosing functions for semivariograms of soil properties and fitting them to sampling estimates. J Soil Sci 1986, 37:617-639.

71. Rossi RE, Mulla DJ, Journel AG, Franz EH: Geostatistical tools for modeling and interpreting ecological spatial dependence. Ecol Monogr 1992, 62(2):277-314

72. Goovaerts P: Geostatistical tools for characterizing the spatial variability of microbiological and physico-chemical soil properties. Biol Fertil Soils 1998, 27(4):315-334.

73. Isaaks EH, Srivastava RM: An Introduction to Applied Geostatistics. Oxford: Oxford University Press; 1989.

74. Cliff AD, Ord JK: Spatial Processes: Models and Applications. London, UK: Pion Ltd.; 1981.

75. Moran PAP: Notes on continuous stochastic phenomena. Biometrika 1950, 37:17-23.

76. Oden NL: Assessing the significance of a spatial correlogram. Geogr Anal 1984, 16(1):1-16

77. Sokal RR, Rohlf FJ: Biometry: The Principles and Practice of Statistics in Biological Research. 3rd edition. New York: W. H. Freeman and Co.; 1995.

78. R Development Core Team: R: A language and environment for statistical computing. In 2151st edition. Vienna, Austria: R Foundation for Statistical Computing; 2010.

79. Bellier E, Monestiez P, Durbec J-P, Candau J-N: Identifying spatial relationships at multiple scales: principal coordinates of neighbour matrices (PCNM) and geostatistical approaches. Ecography 2007, 30:385-399.

80. Peres-Neto PR, Legendre P: Estimating and controlling for spatial structure in the study of ecological communities. Glob Ecol Biogeogr 2010, 19:174-184

81. Dray S, Pélissier R, Couteron P, Fortin M-J, Legendre P, Peres-Neto PR, Bellier E, Bivand R, Blanchet FG, de Cáceres M, Dufour A-B, Heegaard E, Jombart T, Munoz F, Oksanen J, Thioulouse J, Wagner HH: Community ecology in the age of multivariate multiscale spatial analysis. Ecol Monogr 2012, 82:257-275.

82. Blanchet FG, Legendre $P$, Borcard D: Forward selection of explanatory variables. Ecol 2008, 89:2623-2632.

83. Freedman LS, Pee D, Midthune DN: The problem of underestimating the residual error variance in forward stepwise regression. Stat 1992, 41:405-412.

84. Wiens JA: Spatial scaling in ecology. Funct Ecol 1989, 3:385-397.

85. Borcard D, Legendre P, Drapeau P: Partialling out the spatial component of ecological variation. Ecol 1992, 73(3):1045-1055.

86. Peres-Neto PR, Legendre P, Dray S, Borcard D: Variation partitioning of species data matrices: estimation and comparison of fractions. Ecol 2006, 87:2614-2625.

87. Legendre P, Gallagher E: Ecologically meaningful transformations for ordination of species data. Oecologia 2001, 129(2):271-280.

88. Benjamini $Y$, Hochberg $Y$ : Controlling the false discovery rate: A practical and powerful approach to multiple testing. J R Statist Soc B 1995, 57(1):289-300.

89. Verhoeven KJF, Simonse KL, McIntyre LM: Implementing false discovery rate control: increasing your power. Oikos 2005, 108:643-647.

doi:10.1186/s12898-014-0026-4

Cite this article as: Jiménez et al.: Dissecting the multi-scale spatial relationship of earthworm assemblages with soil environmental variability. BMC Ecology 2014 14:26.

\section{Submit your next manuscript to BioMed Central and take full advantage of:}

- Convenient online submission

- Thorough peer review

- No space constraints or color figure charges

- Immediate publication on acceptance

- Inclusion in PubMed, CAS, Scopus and Google Scholar

- Research which is freely available for redistribution

Submit your manuscript at www.biomedcentral.com/submit
C BioMed Central 